\title{
Article \\ Gelatin Reinforced with CNCs as Nanocomposite Matrix for Trichoderma harzianum KUEN 1585 Spores in Seed Coatings
}

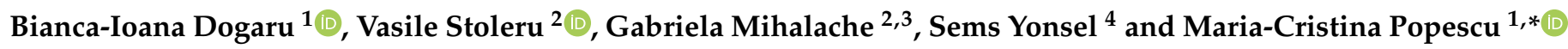 \\ 1 Laboratory of Physical Chemistry of Polymers, Petru Poni Institute of Macromolecular Chemistry, \\ Romanian Academy, 700487 Iasi, Romania; dogaru.bianca@icmpp.ro \\ 2 Department of Horticulture, “Ion Ionescu de la Brad" Iasi University of Life Sciences, 700490 Iasi, Romania; \\ vstoleru@uaiasi.ro (V.S.); gabriela.mihalache.gm@gmail.com (G.M.) \\ 3 Integrated Center of Environmental Science Studies in the North Eastern Region (CERNESIM), \\ Alexandru Ioan Cuza University, 700506 Iasi, Romania \\ 4 ORBA Biokimya San. ve Tic. A.S., Istanbul 34956, Turkey; yonsel@simbiyotek.com \\ * Correspondence: cpopescu@icmpp.ro
}

Citation: Dogaru, B.-I.; Stoleru, V.; Mihalache, G.; Yonsel, S.;

Popescu, M.-C. Gelatin Reinforced with CNCs as Nanocomposite Matrix for Trichoderma harzianum KUEN 1585 Spores in Seed Coatings. Molecules 2021, 26, 5755. https://doi.org/ $10.3390 /$ molecules 26195755

Academic Editor: Joannis K. Kallitsis

Received: 14 June 2021

Accepted: 16 September 2021

Published: 23 September 2021

Publisher's Note: MDPI stays neutral with regard to jurisdictional claims in published maps and institutional affiliations.

Copyright: () 2021 by the authors. Licensee MDPI, Basel, Switzerland. This article is an open access article distributed under the terms and conditions of the Creative Commons Attribution (CC BY) license (https:// creativecommons.org/licenses/by/ $4.0 /)$.

\begin{abstract}
Increasing interest on sustainable agriculture has led to the development of new materials which can be used as seed coating agents. In this study, a new material was developed based on gelatin film reinforced with cellulose nanocrystals (CNC) which was further used as nanocomposite matrix for Trichoderma harzianum KUEN 1585 spores. The nanocomposite films were characterized by Fourier transform infrared spectroscopy (FTIR), X-ray diffraction (XRD) and scanning electron microscopy (SEM), showing the formation of new hydrogen bonds between the components with a good compatibility between them. Measurements of water contact angles and tests of water vapor sorption and swelling degree revealed an improvement in the water vapor absorption properties of the films as a result of their reinforcement with CNC. Furthermore, by adding the Trichoderma harzianum KUEN 1585 spp. in the seed coating material, the germination percentage, speed of germination and roots length of the corn seeds improved. The polymeric coating did not inhibit the growth of T. harzianum KUEN 1585, with this material being a good candidate in modern agriculture.
\end{abstract}

Keywords: gelatin; cellulose nanocrystals; bionanocomposite; seed coating; biofertilizer; germination; plant growth

\section{Introduction}

The economic and environmental future all over the world will profoundly be affected by the development of biodegradable and biocompatible materials derived from renewable resources [1]. In the last decades, to meet the compliance objective, different biopolymers, such as lipids, polysaccharides or proteins [2,3] have been used to synthesize or to produce different polymeric matrices, nano-delivery systems or nanocomposite films due to their biocompatibility, biodegradability and improved mechanical and physical properties. It is known that films based on proteins and polysaccharides have good mechanical properties, but they have high water vapor permeability and are sensitive to moisture, while gelatinbased films have proven to be more resistant and impermeable compared to those produced by polysaccharides [4].

Gelatin is typically obtained from animal bones, skin or ligaments, being a by-product from the meat industry. It is a soluble, flavorless and slightly yellow biopolymer composed of proteins (85-92\%), minerals and water, and it is obtained by partial hydrolysis of collagen [5]. Due to its properties, including its highwater binding and film-forming capacity, gelatin is largely used in many industries, like food, cosmetics and pharmaceutics [6], and shows promising results to be used in the agricultural sector. Its films have good mechanical properties, but do not have sufficient water resistance and exhibit poor barrier properties against water vapors [7]. This is an important disadvantage when gelatin is used in high 
moisture environments because films may disintegrate in contact with water. To optimize the film properties, different nano-sized structures as reinforcing fillers or different plasticizers [8] were studied, thus obtaining nanocomposites with superior properties.

One of the most studied polysaccharide-based nanomaterials in polymer nanocomposites are cellulose nanocrystals (CNC). Generally, CNCs are obtained by acid hydrolysis, degrading the amorphous regions of the cellulose fibers and preserving the crystalline ones. Their dimensions are influenced by the initial source of cellulose, having different widths $(5-20 \mathrm{~nm})$ and lengths $(100 \mathrm{~nm}-2 \mu \mathrm{m})$ [9]. The main properties which make CNCs popular are their biodegradability, renewability, non-toxicity and abundance. They also exhibit high elastic modulus and high tensile strength [10,11]. In their study, Leite et al. [12] observed that by adding only $0.5 \mathrm{wt} \%$ of CNCs led to an increase in tensile strength and Young's modulus of gelatin. Santos et al. (2014) found that gelatin nanocomposites showed high stiffness and good ductility up to $5 \mathrm{wt} \%$ CNCs. Pesticides have been used in agriculture for increasing food productivity since World War II, having a positive impact on pest management. In modern agriculture, to protect germinating seeds and seedlings from insects and soil-borne pathogens, many types of seeds (e.g., corn [13], oilseed rape, cotton, sunflower [14], tomatoes [15], etc.) are coated with active ingredients [16]. However, despite all the advantages, the use of pesticides is avoided nowadays due to the social and environmental damage, and also due to their negative effect on human health [17]. Thereby, a promising alternative is the use of biological and natural agents-biopesticides in a seed-coating formulation $[16,18]$.

Generally, seed coatings consist of an adequate coating material directly applied on seeds, forming a thin and uniform layer. The structural materials used to cover the seeds are classified into binders, fillers, active ingredients, polymer matrix and water [19]. It is important that coating agent can adhere to seeds, and once planted, have a positive impact on germination and seedling vigor. Therefore, biodegradable polymers can be used as coating material because they can serve as nutrients for biocontrol agents [20].

One of the widely studied biocontrol agents is Trichoderma spp., with good results on soil or seeds as a growth-promoting agent or applications against several foliar diseases [21].

The aim of this study was to reinforce gelatin films with CNCs through the solvent casting method, and the films' structural features and properties were evaluated. Furthermore, the feasibility of using gelatin-based corn seed coating incorporated with biofertilizer fungus Trichoderma harzianum KUEN 1585 and its impact on germination of corn seeds was tested. The originality of this study exists in the use of $\mathrm{CNC}$ as a nanofiller which can provide moisture absorption and retention capability to help seed germination and to enhance the shelf life of microbial fertilizers at ambient conditions. Moreover, the development of microbial formulations requires the use of biocompatible materials.

\section{Results and Discussions}

\subsection{Film Characterization}

\subsubsection{Fourier Transform Infrared Spectroscopy}

Infrared spectroscopy was used to identify the chemical structure and the interactions established between the pure components during the preparation of the film. Because the spectrum of the CNC partially overlaps with the spectrum of gelatin, to provide evidence of the interactions taking place in the composites the experimental spectra and their derivatives were compared with the calculated ones (using the components' spectra and the low additivity) [22]. For an immiscible blend, the calculated and the experimental spectra should be the same, while for a miscible blend, differences can occur due to the interactions between the components [23].

FTIR spectra and their derivatives of the composite films and their components are presented in Figure 1. The spectra were separated in two regions: $3750-2700 \mathrm{~cm}^{-1}$ assigned to stretching vibration of hydroxyl and methyl/methylene groups and "fingerprint region" between $1800-800 \mathrm{~cm}^{-1}$. 

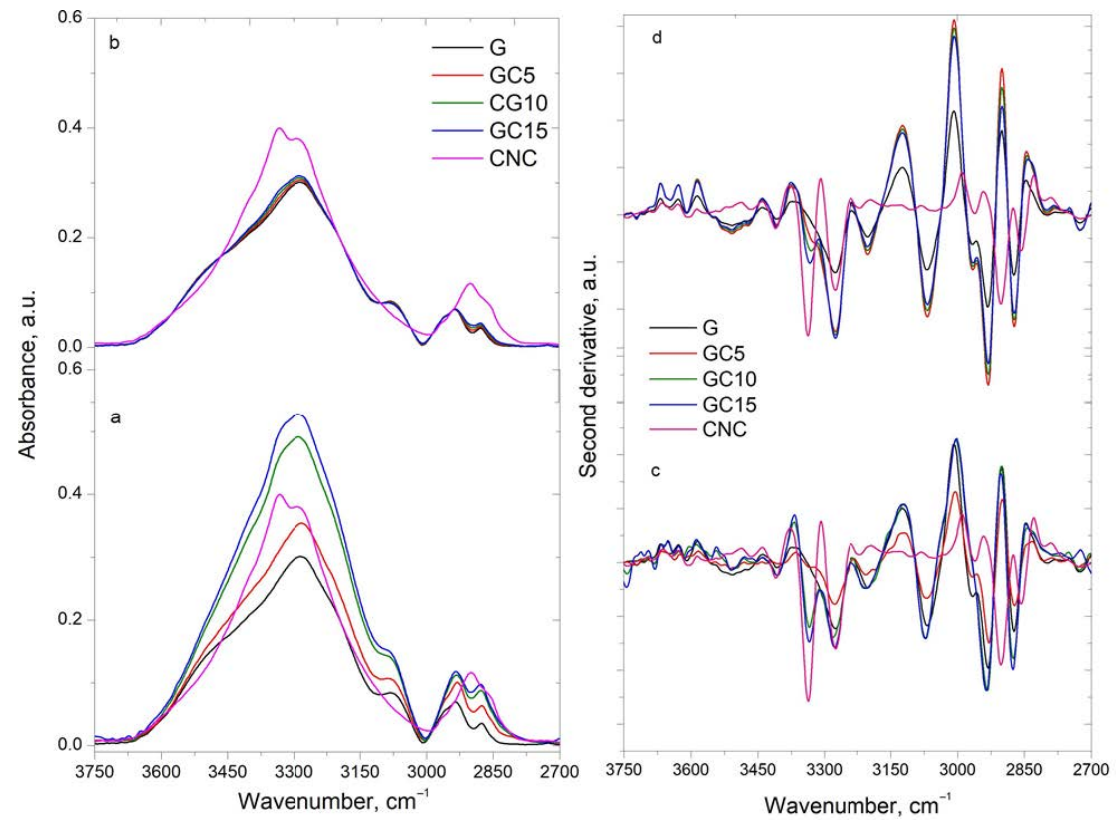

Figure 1. Experimental and calculated FTIR spectra $(\mathbf{a}, \mathbf{b})$ and their derivatives $(\mathbf{c}, \mathbf{d})$ in the $3750-2700 \mathrm{~cm}^{-1}$ region.

From the experimental spectra small differences can be observed, but the second derivative spectra highlight the main differences among the spectra, mostly in the $\mathrm{CH}$ stretching vibration region [24]. The experimental and calculated spectra and their second derivatives of the samples in the region $3750-2700 \mathrm{~cm}^{-1}$ are presented in Figure 1.

It can be seen that both components have a broad band in the 3750 and $3000 \mathrm{~cm}^{-1}$ regions assigned to different stretching vibrations of $\mathrm{OH}$ groups, and two bands in the $3000-2700 \mathrm{~cm}^{-1}$ spectral region assigned to symmetric and asymmetric stretching vibration of $\mathrm{CH}_{3}$ and $\mathrm{CH}_{2}$ groups [24].

By analyzing the second derivative spectra of the pure components, the following bands are highlighted. For gelatin, characteristic bands can be observed at $3408 \mathrm{~cm}^{-1}$ assigned to of N-H and O-H stretching vibrations (amide A) [25], at 3272 and $3144 \mathrm{~cm}^{-1}$ assigned to free $\mathrm{N}-\mathrm{H}$ groups and to $\mathrm{H}$-bonded $\mathrm{N}-\mathrm{H}$ groups, and at $2932 \mathrm{~cm}^{-1}$ assigned to stretching of $\mathrm{C}-\mathrm{H}$ and $-\mathrm{NH}_{3}{ }^{+}$(amide B) [12]. For cellulose nanocrystals a broad band at $3410 \mathrm{~cm}^{-1}$ is observed in the spectrum. This is actually composed of a series of subbands corresponding to different intermolecular and intramolecular hydrogen bonds in cellulose I: $3566 \mathrm{~cm}^{-1}$ assigned to free $\mathrm{OH}(6)$ and $\mathrm{OH}(2)$ in cellulose and weakly absorbed water, $3411 \mathrm{~cm}^{-1}$ assigned to $\mathrm{O}(2) \mathrm{H} \ldots \mathrm{O}(6)$ intramolecular hydrogen bonds and results in the formation of crystalline regions in cellulose, $3336 \mathrm{~cm}^{-1}$ assigned to $\mathrm{O}(3) \mathrm{H} \ldots \mathrm{O}(5)$ intramolecular hydrogen bonds in cellulose, 3275 and $3223 \mathrm{~cm}^{-1}$ assigned to $\mathrm{O}(6) \mathrm{H} \ldots \mathrm{O}(3)$ intermolecular hydrogen bonds in cellulose monoclinic $\mathrm{I} \beta$ and triclinic $\mathrm{I} \alpha$ phases. In the methyl/methylene region, three bands are observed in the second derivative spectrum of CNC at 2961, 2903 and $2853 \mathrm{~cm}^{-1}$ assigned to symmetric stretching vibration of methyl and methylene groups [25].

From the theoretic spectra, all the bands observed in the composite spectra are only a sum of intensities of the component bands, presenting higher intensities and increasing proportionally with the concentration of the components in the blends. Moreover, they present a similar position with the bands found in gelatin (the component with the higher concentration), with the exception being observed for the band from $3337 \mathrm{~cm}^{-1}$ which is present only in the $\mathrm{CNC}$ spectrum. This later band is increasing in intensity proportionally with the increase in the CNC content.

By comparison, the experimental second derivative spectra show differences as follows: the band from $3337 \mathrm{~cm}^{-1}$ (in $\mathrm{CNC}$ ) (assigned to $\mathrm{O}(3) \mathrm{H}$... O (5) intramolecular 
hydrogen bonds) is shifted to $3332 / 3334 \mathrm{~cm}^{-1}$ in the composite spectra and the intensity does not increase proportionally with the increase in the CNC content (as in the case of calculated spectra); the band from $3275 \mathrm{~cm}^{-1}$ (in CNC) $/ 3276 \mathrm{~cm}^{-1}$ (in G) (assigned to intermolecular hydrogen bonds) is shifted to a higher wavenumber in the composite spectra (to $3278-3281 \mathrm{~cm}^{-1}$ ) and presents lower intensity when comparing to component spectra and also comparing to the same band from the calculated spectra. Furthermore, the band from $3067 \mathrm{~cm}^{-1}$ (in G) (assigned to CNH bending vibration) is shifted to $3072 \mathrm{~cm}^{-1}$ in composite spectra and also shows a lower intensity when comparing to the one from the calculated spectra. It is also interesting to note that the band from $2961 / 2967 \mathrm{~cm}^{-1}$ (in CNC/G) (assigned to symmetric stretching vibration of methyl and methylene groups) is not observable in the composite spectra with $10 \%$ and $15 \%$ CNC, while the band from $2903 \mathrm{~cm}^{-1}$ (in $\mathrm{CNC}$ ) (assigned also to symmetric stretching vibration of methyl and methylene groups) is not visible at all in the composite spectra.

All these differences observed between the calculated and experimental spectra indicate the presence of interactions taking place between the gelatin and CNC via hydrogen bonds.

In the fingerprint region, the characteristic bands for gelatin appear at $1683 \mathrm{~cm}^{-1}$ assigned to $\beta$-Turn [26], at $1668 \mathrm{~cm}^{-1}$ assigned to amide I: $\mathrm{C}=\mathrm{O}$ stretch/hydrogen bond coupled with $\mathrm{COO}^{-}$, and at $1626 \mathrm{~cm}^{-1}$ assigned to amide $\mathrm{I}(\mathrm{C}=\mathrm{O}$ stretching vibration of amide and a small contribution of $\mathrm{C}-\mathrm{N}$ stretching vibration); the band with a maximum at $1519 \mathrm{~cm}^{-1}$ assigned to amide II (C-N stretching vibration and N-H bending vibration), and the band from $1237 \mathrm{~cm}^{-1}$ assigned to amide III (C-N stretching vibration coupled to $\mathrm{N}-\mathrm{H}$ bending vibrations with small contribution from $\mathrm{C}-\mathrm{C}$ stretching and $\mathrm{C}=\mathrm{O}$ in plane bending vibration) [27]. The band from $1519 \mathrm{~cm}^{-1}$ is a large band which includes both types of vibrations for the $\alpha$-helical structure (with a maximum at $1550-1540 \mathrm{~cm}^{-1}$ ) and $\beta$-sheets structure (at $1525-1520 \mathrm{~cm}^{-1}$ ) [28].

Other important bands in the fingerprint region of the gelatin spectrum are observed at $1447,1395,1279,1197,1159,1116,1081,1028$ and $971 \mathrm{~cm}^{-1}$. These are assigned to the $\mathrm{CH}$ deformation vibration, $\mathrm{OH}$ in plane deformation vibration, $\mathrm{CH}$ bending vibration, $\mathrm{C}-\mathrm{N}$ stretching vibration in amine groups, $\mathrm{C}-\mathrm{O}-\mathrm{C}$ stretching vibration, $\mathrm{C}-\mathrm{C}$ stretching vibration and C-O stretching vibration, respectively [23-25].

In addition, the spectrum of CNC shows some characteristic bands at 1458, 1427, 1369, 1337,1314 and $1275 \mathrm{~cm}^{-1}$ assigned to stretching and deformation vibration of $\mathrm{CH}$ groups; at $1203,1159,1107$ and $1055 \mathrm{~cm}^{-1}$ assigned to stretching and deformation vibration of $\mathrm{C}-\mathrm{O}-\mathrm{C}$ and $\mathrm{C}-\mathrm{O}$ groups [23]. As for the previous region, the calculated spectra (Figure 2b,d) indicate similar bands to gelatin or $\mathrm{CNC}$, which vary in intensity proportionally with the variation of the concentration of the components. However, this is not the case for the experimental spectra (Figure 2a,c), where a large number of bands vary in intensity and position.

The amide I region from gelatin structure has been extensively used to probe the protein structure and dynamics due to its sensitivity to the backbone conformation of a protein. It can also provide useful information about protein folding, misfolding and unfolding, as this spectral region is composed of overlapping bands arising from $\alpha$-helices, $\beta$-sheets and nonordered structures. This vibrational mode comes from the stretching vibration of $\mathrm{C}=\mathrm{O}$ from the peptide group, which is weakly coupled with the C-N stretching and in-plane $\mathrm{N}-\mathrm{H}$ bending vibration $[29,30]$. The spectrum of pure gelatin presents two small bands at 1683 and $1668 \mathrm{~cm}^{-1}$ (visible more like shoulders than individual bands) and a strong band at $1626 \mathrm{~cm}^{-1}$, which are shifted to higher $\left(1691,1628 \mathrm{~cm}^{-1}\right)$ and lower $\left(1652 \mathrm{~cm}^{-1}\right)$ wavenumber values in the composites' spectra. Moreover, the band from $1691 \mathrm{~cm}^{-1}$ becomes visible as a band in the composites with $10 \%$ and $15 \% \mathrm{CNC}$, while the one from $1652 \mathrm{~cm}^{-1}$ appears like a strongly connected shoulder to the band from $1628 \mathrm{~cm}^{-1}$.

The shifting of the bands to higher/lower wavenumber is observed only in the experimental spectra, being an indicator that the reinforcing agent $(\mathrm{CNC})$ influenced the gelatin structure and conformation. 

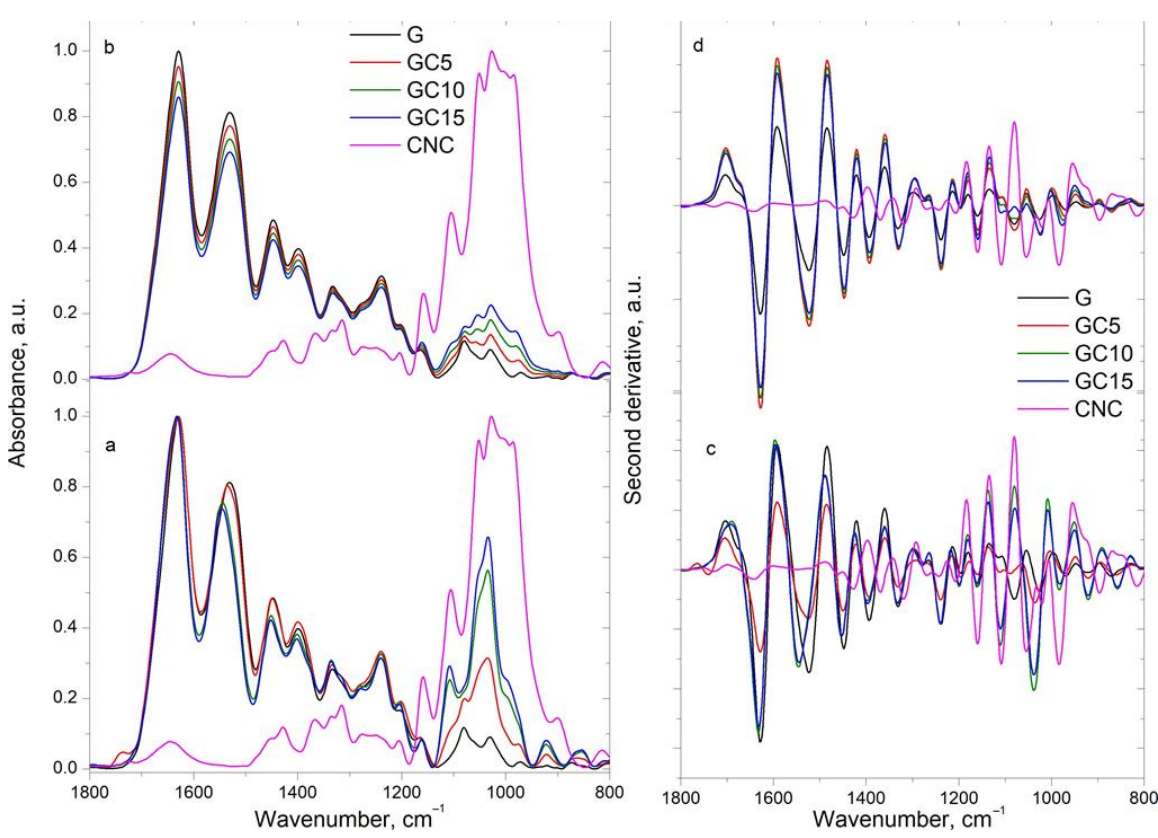

Figure 2. Experimental and calculated FTIR spectra $(\mathbf{a}, \mathbf{b})$ and their derivatives $(\mathbf{c}, \mathbf{d})$ in the $1800-800 \mathrm{~cm}^{-1}$ region.

In experimental spectra, the band corresponding to amide II from $1519 \mathrm{~cm}^{-1}$ (in G) presents a small shoulder at $1542 \mathrm{~cm}^{-1}$ (assigned to C-O stretching vibration) in the GC5 composite spectrum, which is shifted to $1548 \mathrm{~cm}^{-1}$ in CG10 and CG15 composite spectra and appears as a well-defined band with a small shoulder at $1521 \mathrm{~cm}^{-1}$. On the other side, in the calculated spectra this band remains unchanged $\left(\right.$ at $\left.1518 \mathrm{~cm}^{-1}\right)$. The amide II band is assigned to $\mathrm{N}-\mathrm{H}$ bending and $\mathrm{CN}$ stretching vibrations. The modification of this band may indicate the changes in the hydrogen bonds near the peptide chains, therefore this modification might be due to the formation of new hydrogen bonds between $\mathrm{O}-\mathrm{H}$ groups of $\mathrm{CNC}$ and $\mathrm{N}-\mathrm{H}$ groups of proteins which partially weakens and perturbs the internal hydrogen bond network in gelatin [31].

Further modifications can be observed for the band from $1395 \mathrm{~cm}^{-1}$ (in G) (assigned to stretching vibration of $\mathrm{C}-\mathrm{N}$ bonds [32]), which in the calculated spectra remain unchanged but in the experimental spectra is shifted to $1400 \mathrm{~cm}^{-1}$. In the spectra of the composites with $10 \%$ and $15 \% \mathrm{CNC}$, in their composition a new band at $1378 \mathrm{~cm}^{-1}$ can be identified. This later band it is assigned to $\mathrm{CH}$ deformation vibration in $\mathrm{CNC}$ and is shifted to a higher wavenumber compared to the pure component.

Other important modifications observed in the experimental spectra comparing to the calculated ones are in the $1130-1000 \mathrm{~cm}^{-1}$ region. Thus, the band from $1116 \mathrm{~cm}^{-1}$ (in $\mathrm{G}) / 1107 \mathrm{~cm}^{-1}$ (in CNC) assigned to C-O-C stretching vibration in both components is shifted to $1111 \mathrm{~cm}^{-1}$ in the composite spectra; the band from $1081 \mathrm{~cm}^{-1}$ (in G) assigned to $\mathrm{C}-\mathrm{O}$ stretching in gelatin decreases in the composite spectra, being observable only as a shoulder in GC15 composite, and is shifted to $1086 \mathrm{~cm}^{-1}$. In the calculated spectra, this band decreases in intensity proportionally with the increase of the CNC content. The bands from $1059 \mathrm{~cm}^{-1}$ (observable as a shoulder in G) $/ 1028 \mathrm{~cm}^{-1}$ and 1055/1026 cm ${ }^{-1}$ (in CNC) assigned to C-O stretching vibration in both components are shifted to 1053 and $1032 \mathrm{~cm}^{-1}$, respectively. The first band appears as a well-defined band, while the second band presents a strong increase in intensity in the GC10 and GC15 composite spectra. Again, these bands intensity varies proportionally with the $\mathrm{CNC}$ content in the calculated spectra, while is not the case in the experimental ones.

Furthermore, the band from $920 \mathrm{~cm}^{-1}$ assigned to $\mathrm{OH}$ bending vibration increased in intensity in the experimental spectra of the composites but presented almost the same intensity in the calculated spectra. Clear differences by variation of band position and in- 
tensity in the experimental spectra comparing to calculated ones were observed, indicating the presence of chemical interactions taking place between the $\mathrm{C}-\mathrm{O}, \mathrm{C}-\mathrm{OH}$ and $\mathrm{N}-\mathrm{H}$ groups of the two components via hydrogen bond interactions.

\subsubsection{X-ray Diffraction (XRD)}

$X$-ray diffraction analysis allows us to examine the microstructure of the polymeric composite films. Having an in-depth perception of the microstructure is very important when studying new materials, since it influences their physical and mechanical properties. The obtained diffraction patterns are depicted in Figure 3.

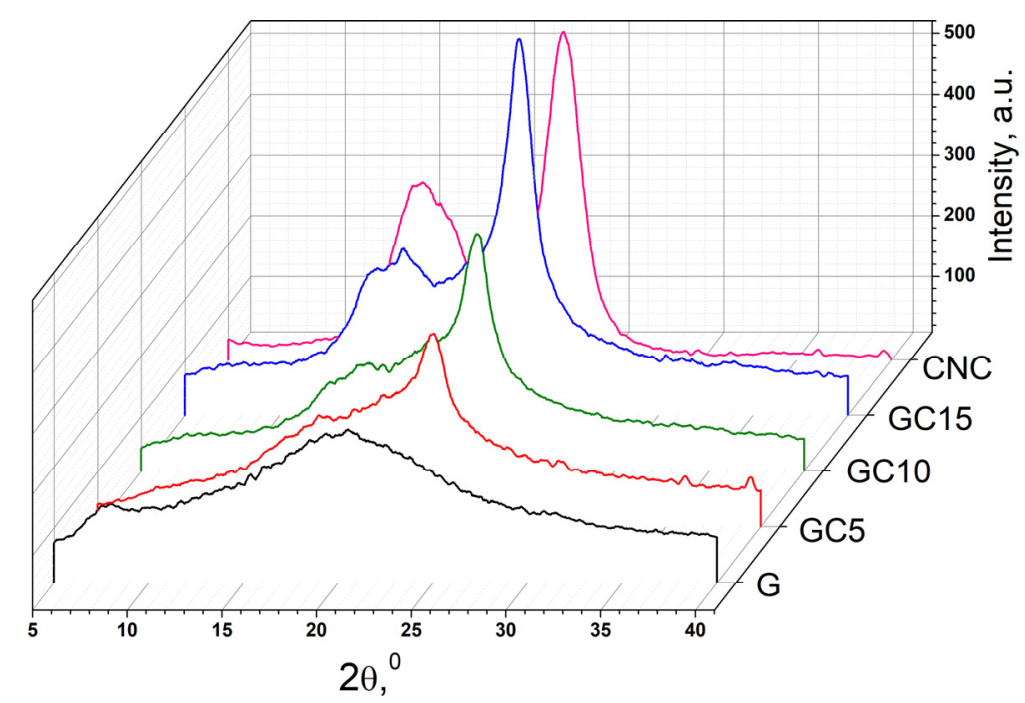

Figure 3. X-ray diffraction (XRD) patterns of gelatin, $\mathrm{CNC}$ and gelatin-based nanocomposite films.

Gelatin films present a broad signal at $2 \theta$ of $20^{\circ}$ assigned to the high content of amorphous faction and to the distance between adjacent polypeptide strands of $G$ [33] and a small band at $7.7^{\circ}$ assigned to triple-helix crystalline structures [32]. CNC diffractogram presented typical signals of cellulose I, such as: $15.2^{\circ}$ signal assigned to the (1-10) plane, $16.4^{\circ}$ signal assigned to (110) plane, $20.3^{\circ}$ signal corresponding to (102) plane and $22.6^{\circ}$ signal assigned to the (200) crystallographic plane [23,34]. The signals from $16.4^{\circ} 2 \theta$ and $20.3^{\circ} 2 \theta$ merged with the ones from $15.3^{\circ} 2 \theta$ and $22.6^{\circ} 2 \theta$, being almost unnoticeable [35]. In the composite films, with the addition of CNC in gelatin matrix, the signals from $2 \theta=15.3^{\circ}$ and $22.6^{\circ}$ increase in intensity. This can be correlated with the increasing of overall crystallinity in blends compared with gelatin film and can be a consequence of the formation of strong hydrogen bonds between the components [25]. Moreover, the signals from $15.3^{\circ}$ and $16.4^{\circ}$ are more visible in the diffractograms of the composite films and are shifted to higher values (to $15.5^{\circ}$ and to $16.7^{\circ}$ ), indicating that interactions took place between the cellulose nanocrystals and gelatin matrix. These can be due to a rearrangement in the orientation of CNC crystallites after incorporation in the polymeric matrix [36]. Furthermore, with the addition of CNC, the band from $7.7^{\circ}$ assigned to triple-helix crystalline structures from gelatin and the broad reflection from $20^{\circ}$ decrease in intensity, being an indicator that the triple-helical structure is denaturated and the CNC interacts with the semicrystalline arrangement of the gelatin matrix [37].

\subsubsection{Scanning Electron Microscopy (SEM)}

The surface morphology of gelatin-based nanocomposite films was evaluated by SEM (Figure 4). 

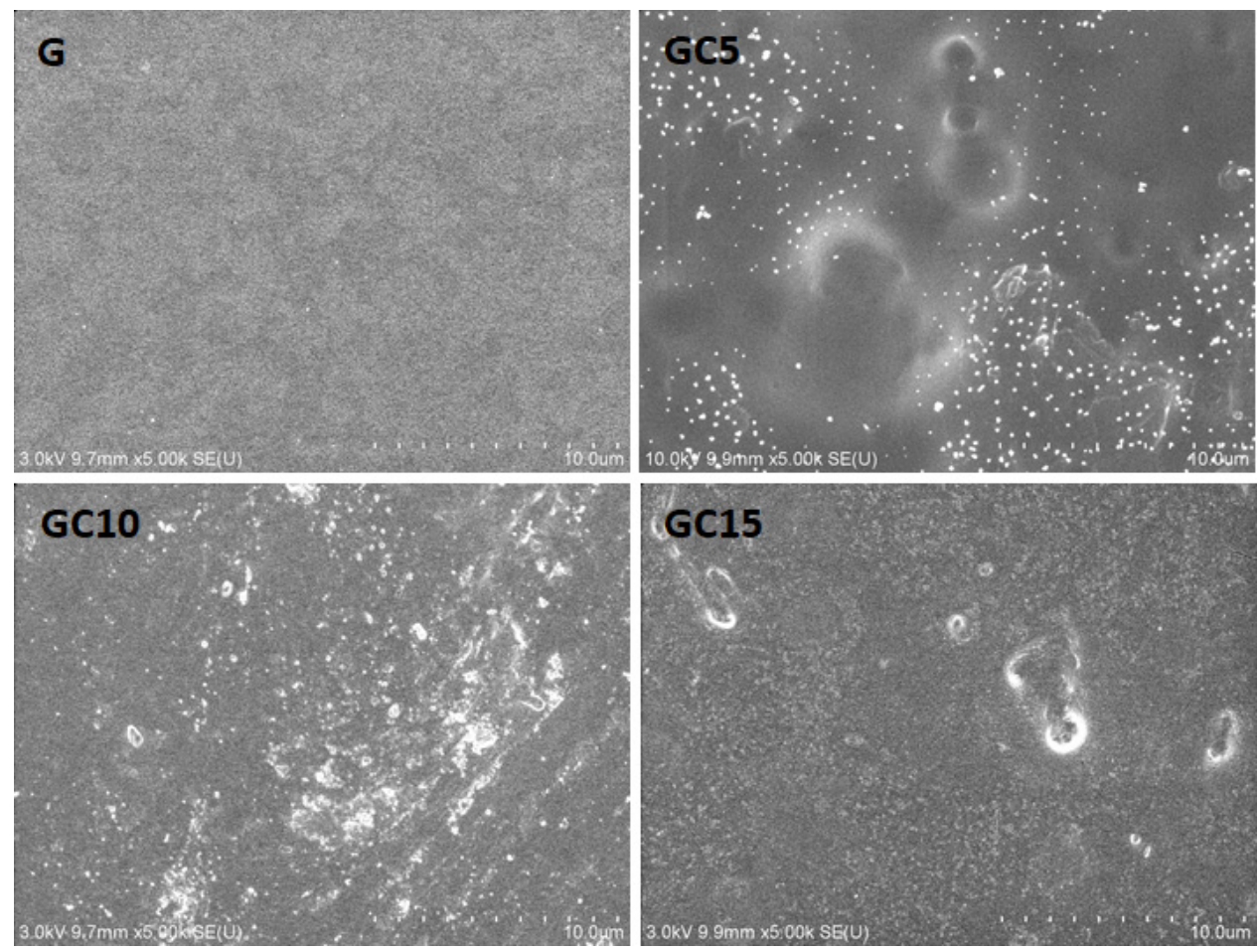

Figure 4. Morphological aspect of gelatin films reinforced with CNC.

Gelatin film exhibited a smooth and continuous surface due to the homogenous network structure. Adding CNC into the polymeric matrix led to a less smooth surface, indicating a microstructural change in the polymeric matrix, but the distribution of CNC is homogenous. However, the presence of white dots may be due to the appearance of some small cellulose nanocrystals aggregates and cross-sections of the nanocrystals added in the polymer matrix. These observations were also reported in the literature [12]. Li et al. [38] observed the formation of aggregation or inhomogeneous dispersion of CNC in the CMC matrix at higher than $7 \%$ content of the former one. Similar results were obtained by Mondragon et al. [39] when adding CNF into a gelatin matrix and by Popescu et al. [22] when CNC was added into $\mathrm{K}$-carrageenan nanocomposite films.

\subsubsection{Water Vapor Sorption Measurements}

An important property of the coating materials is their behavior in contact with water molecules. Gelatin film exhibits a poor water vapor barrier property due to its hydrophilic characteristics of being a hygroscopic material, absorbing water depending on the $\mathrm{RH}$ at which it was stored [40]. The water sorption process implies the progressive penetration of water molecules through the polymeric matrix by chemisorption, physical adsorption and multilayer condensation. Generally, according to Van der Wel and Adan [41], the adsorption isotherms can be divided into three regions: a first region assigned to the single water molecules that do not show important interactions with other water molecules or with their environment; a second region assigned to water molecules which interact with other water molecules and form clusters or aggregates but are not big enough to have bulk water properties; and third region which is specific to the interaction of polymeric groups with the water molecules [42].

The adsorption isotherms of the gelatin and composite films represented as the moisture content as a function of relative humidity are shown in Figure 5. 


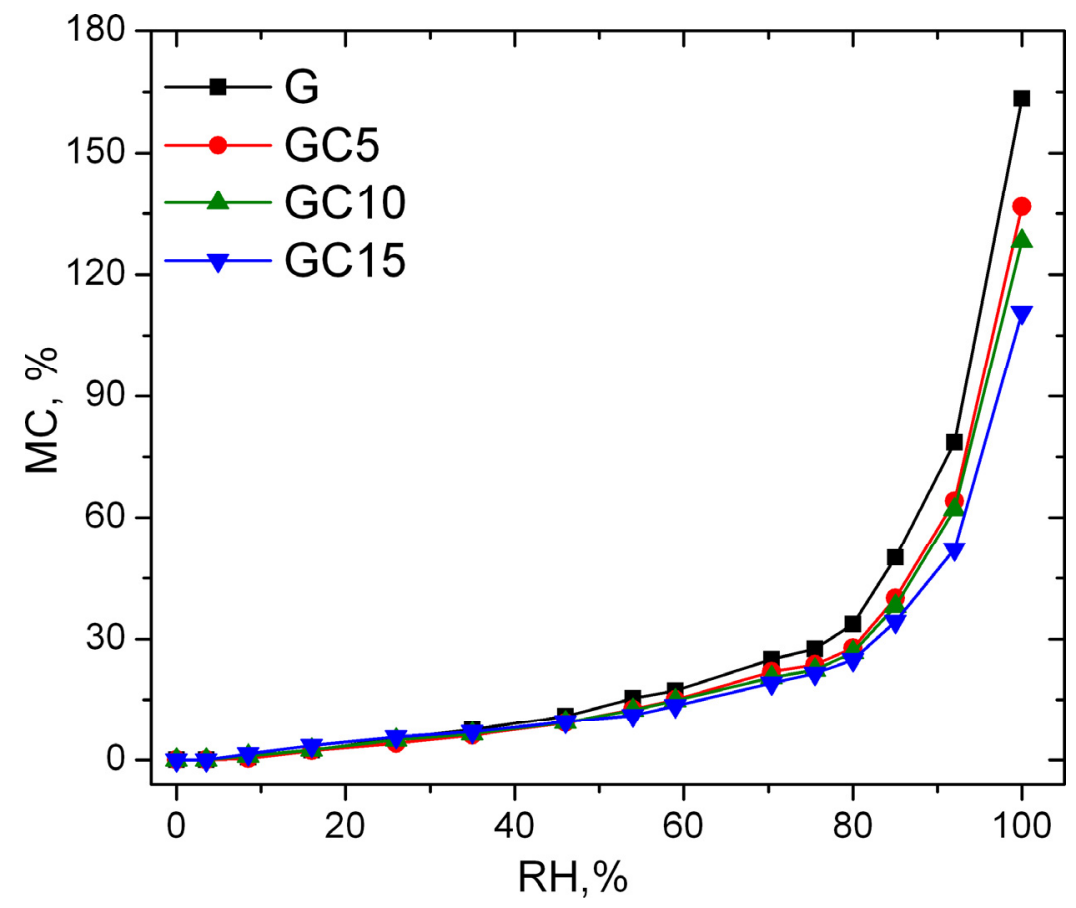

Figure 5. Sorption isotherms of the samples as a function of RH.

As mentioned by Van der Wel, at lower values of relative humidity, the samples adsorb a small amount of water, and up to $45 \% \mathrm{RH}$ all the samples exhibit almost the same behavior. After this $\mathrm{RH}$ value, the neat gelatin film starts to be more sensitive to water molecules compared to nanocomposite films. Over $70 \% \mathrm{RH}$, the sorption isotherms start to have an asymptotic increase. At $100 \% \mathrm{RH}$, the maximum MC value decreases with the increase of CNC content in the composite films, with neat gelatin film having about $163 \%$ MC, GC5-136\%, GC10-128\% and GC15-110\%. The later one has a maximum MC 53\% lower than in case of gelatin film.

This behavior may be a consequence of dispersion of nanofiller in the polymeric matrix, the presence of $\mathrm{CNC}$ in gelatin matrix causing a tortuous path for the water vapor molecules to enter through the films, and as observed by FTIR spectroscopy, intermolecular interaction between both polymers takes place due to the formation of hydrogen bonding throughout the polymer chain. Moreover, because of good interaction between the polymers, a more compact structure of film matrix results. This might be able to control and restrict the adsorption of water molecules. Ooi et al. [43] mentioned in their study that the reduction of water vapor sorption might be due to the increase in the crystallinity of the samples due to the introduction of CNCs or by reducing the available sorption sites (the free $\mathrm{OH}$ and NH hydrophilic groups) in the gelatin matrix, while George and Siddaramaiah [44] attributed the reduction of water vapor sorption ability to low hygroscopicity of highly crystalline CNCs.

To highlight the presence of water molecules in the composite films, NIR spectroscopy was used. The band from about $1940 \mathrm{~nm}$ is highly sensitive to the presence of water molecules being assigned to their stretching vibration. Figure 6a shows the integral area of this band in the case of GC15 composite film. The integral area increases with the increase of the MC in the films and the moisture content shows a linear dependence $\left(R^{2}: 0.99\right)$ when it is plotted as a function of the integral area of this band (Figure 6b). 


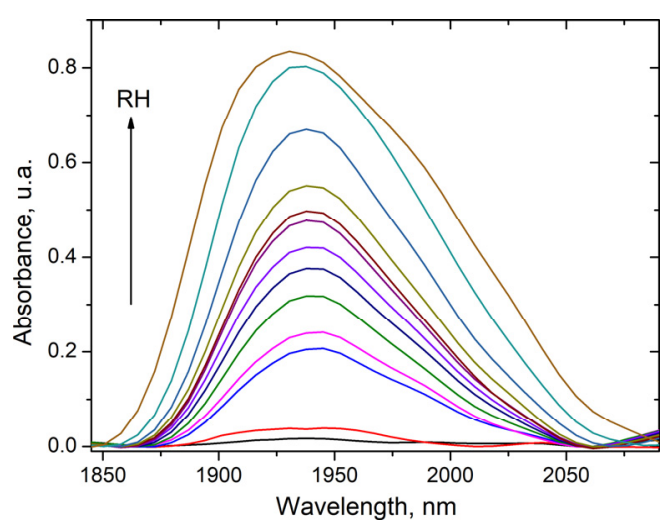

(a)

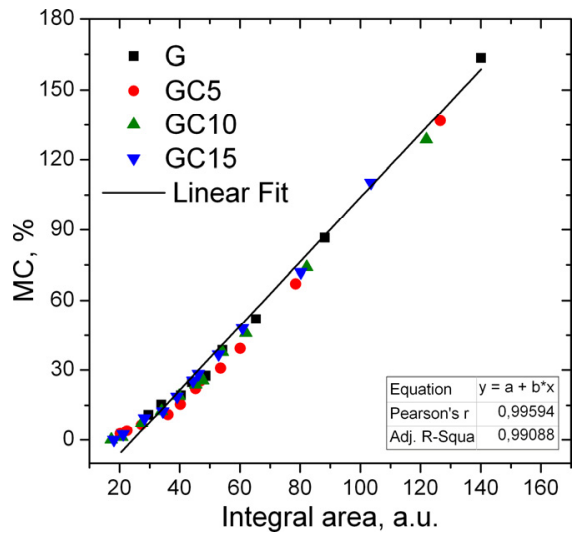

(b)

Figure 6. The band at $1940 \mathrm{~nm}$ for the GC15 sample in the sorption process (a), and the integral area plotted as a function of the MC for gelatin and composite films (b).

\subsubsection{Moisture Adsorption Test}

Generally, gelatin, CNC and glycerol are hydrophilic polymers and therefore can bind with water molecules, forming new hydrogen bonds [45]. Moreover, the porous structure of gelatin network can contribute to the easy absorbance of water molecules [46]. The value of moisture absorption of samples can be an indicator of water content within the composite films.

By exposing the films at $57 \% \mathrm{RH}$ for $24 \mathrm{~h}$, the moisture adsorption remained almost constant after $6 \mathrm{~h}$.

The measured maximum moisture adsorption for gelatin film was $11.5 \%$ after $24 \mathrm{~h}$ (Figure 7a). The values decrease when CNC is added in the composite films. The lowest value for moisture adsorption was observed in case of the GC15 $(6.8 \%)$ sample, being about 39\% lower than in the case of gelatin film. In the case of nanocomposite films, due to hydrogen bonding interactions which took place between gelatin and $\mathrm{CNC}$, the water uptake may be reduced because of reduction of chances of water molecules to bond to sorption sites.

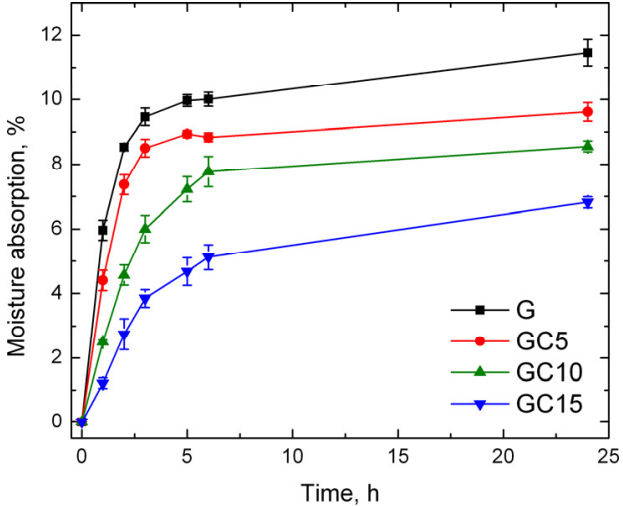

(a)

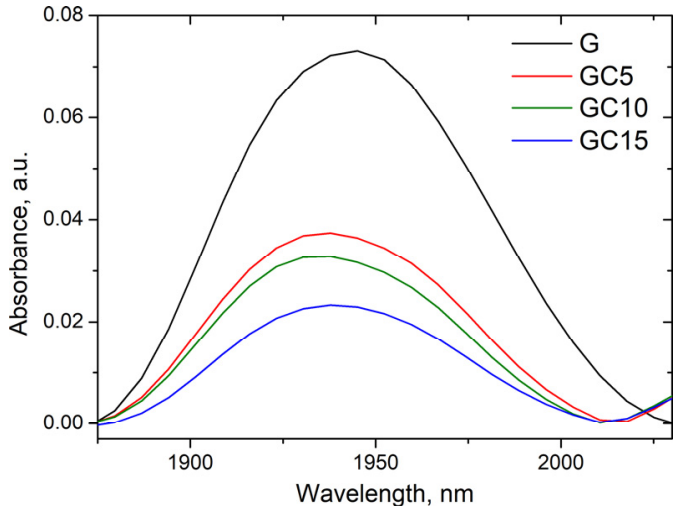

(b)

Figure 7. Moisture adsorption after exposing the gelatin and composite films at $57 \%$ for $24 \mathrm{~h}$ (a) and the NIR band from $1940 \mathrm{~nm}$ at $57 \%$ RH after $24 \mathrm{~h}$ of exposure (b).

Furthermore, Figure $7 \mathrm{~b}$ plots the bands corresponding to adsorbed water in the films at $57 \%$ RH. The integral area of these bands is 5.9 (for G), 2.82 (for GC5), 2.42 (for GC10) and 1.67 (for GC15), showing a decrease with the increasing CNC content. These results agree with the results presented above. 
The moisture content at equilibrium depends on the morphology (macro-voids, crystal size and crystallinity degree) and hydrophilicity of the nanocomposite films. Similar results were obtained by Syahida et al. [45] when adding palm wax into a fish gelatin matrix. Furthermore, Santos et al. [47] observed a decreased water transmission through gelatincellulose whisker films, which could be attributed to the reduction of amorphous areas and to a dense composite structure caused by the hydrogen-bonded percolating network of cellulose whiskers. Miao et al. mentioned in their study that "the uniform dispersion of the cellulose nanocrystals in the nanocomposite films would likely help block the permeating path of small molecules, and could thus contribute to the high barrier performance of the final nanocomposite film" [48].

\subsubsection{Determination of Swelling Degree}

For swelling degree determination, the samples were immersed in distilled water. The gelatin film was completely dissolved after $5 \mathrm{~min}$, but with an increase of the reinforcing agent, the resistance of samples increased (Figure 8).

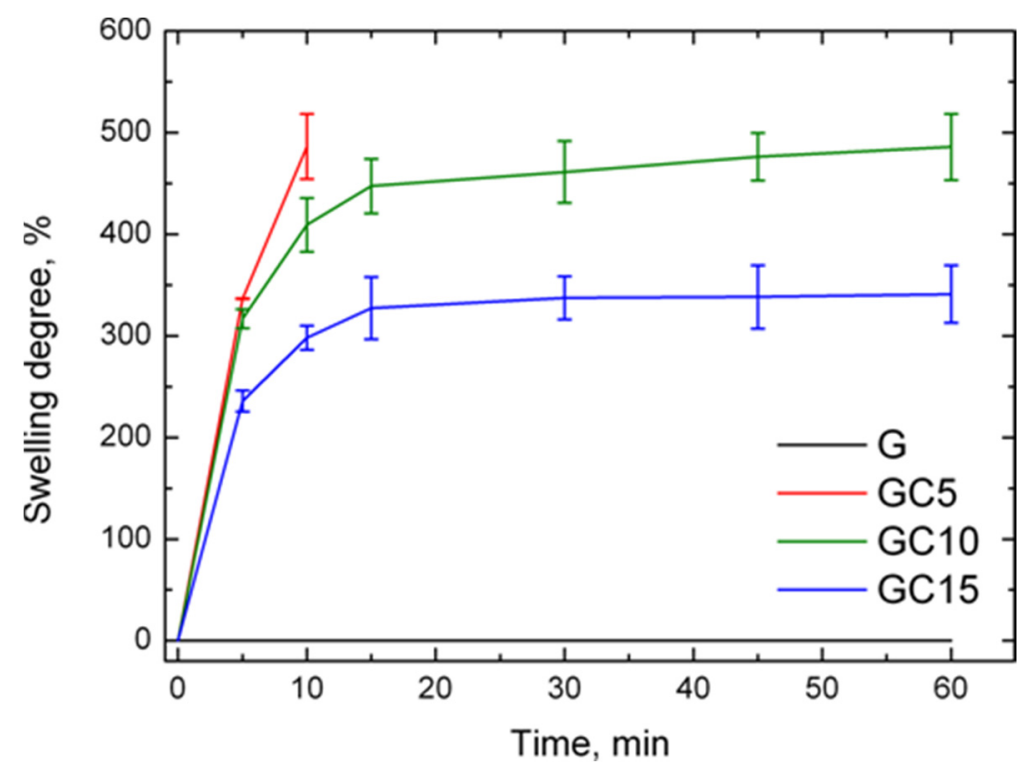

Figure 8. Swelling degree of gelatin and composite films immersed in water for $60 \mathrm{~min}$.

The GC5 film after 10 min reached a swelling degree of almost 500\% and after that the sample was dissolved. The other two composite films did not dissolve in water and reached a swelling degree of about 480\% (GC10) and approximately 320\% (GC15), respectively. As observed by FTIR spectroscopy, due to interactions taking place between the polymer matrix and reinforcement agent, a more compact structure of film was created. The increased resistance of the films can be attributed to the formation of intermolecular hydrogen bonds between hydroxyl groups of CNC and amino groups of gelatin chains, reducing their ability to interact with water molecules. Maroufi et al. [49] found in their study that the addition of modified carrageenan in gelatin reduced the solubility and moisture content of the films. They mentioned that this is due to the formation of crosslinking bonds between the amino groups from gelatin and the dialdehyde from modified carrageenan, leading to a denser structure with reduced water absorption ability and water binding capacity. In another study, Xiao et al. [50], using soy protein, CNC and zinc oxide nanoparticles, observed that the water solubility of the nanocomposite films was significantly reduced following the addition of CNC-containing agents. They mentioned that this reduction was due to "the formation of hydrogen bonds between the hydrophilic groups of protein and the surface hydroxyl groups of CNC which improved the cohesiveness and compactness of the film matrix, and thus decreasing the water sensitivity". 


\subsubsection{Water Contact Angle Measurements}

Figure 9 shows the contact angle values of the studied films. All films, including the pure gelatin film, had contact angle values higher than $90^{\circ}$, which indicates that all the surface samples were slightly hydrophobic.

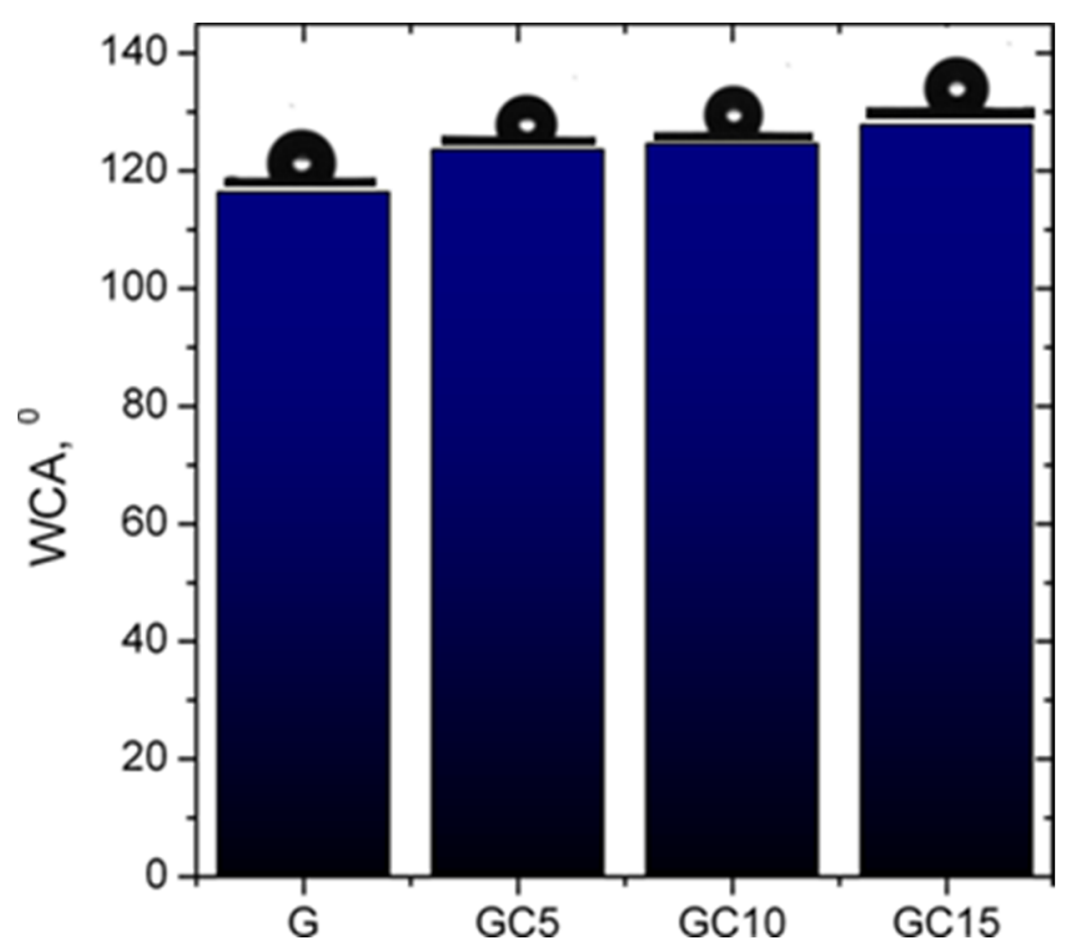

Figure 9. Values for water contact angles of the studied films and the images of the droplets on the surfaces of the samples.

G film exhibited the lowest value for water contact angle $\left(116^{\circ}\right)$, which indicates it has more hydrophilic behavior compared to composite films. This is due to the fact that the polar amino acids in the gelatin backbone are more susceptible to moisture absorption [11]. Adding CNCs to gelatin increased the water contact angle value to $123^{\circ}$ for GC5, to $124^{\circ}$ for GC10 and to $127^{\circ}$ for GC15 film. This could be due to formation of hydrogen bonds between gelatin polar groups and CNC hydroxyl groups [12], but also to a higher roughness due to $\mathrm{CNCs}$ dispersion within the gelatin matrix. Ahammed et al. [32] observed that WCA was $104.8^{\circ}$ for gelatin film and the surface roughness induced by addition of zein in the films can significantly affect WCA values, decreasing it up to $50^{\circ}$. Moreover, Pereira et al. [37] found that the gelatin-based films exhibited values of WCA between $90^{\circ}$ and $98^{\circ}$, with these values being influenced by the incorporation of $\mathrm{ZnO}$, indicating that the increase of nanoparticle concentration enhanced the WCA of the films. Corrêa de Souza Coelho et al. [51] observed that adding CNCs into the starch matrix led to an increase of the WCA compared to starch control film, but this improvement was dependent on the content of the CNCs in the matrix. Therefore, for the incorporation of an amount up to $10 \%$ of CNCs the WCA increased, with this "behaviour corresponding to highly crystalline, hydrophobic characteristics of CNCs". When the authors used a higher concentration of CNCs (15\%), they observed similar values of the WCA with the control film. They mentioned that this can be due to a "possible aggregation caused by the higher CNC concentration in the matrix". However, this behavior was not observed in our case, where the addition of $15 \%$ CNCs into the polymeric matrix induced a further increase in the contact angle. 


\subsubsection{Dry-In Time of Water Droplets on the Surfaces and Absorption}

The dry-in time of a water droplet is dependent on the relative humidity of the surrounding environment, being closely related to the contact angle and adsorption behaviors. If the ability of adsorption is high and the CA is low, the water droplets dry faster.

The upper side of Figure 10 shows the water droplets on the films immediately after dropping them and the lower side images show the water droplets after drying.
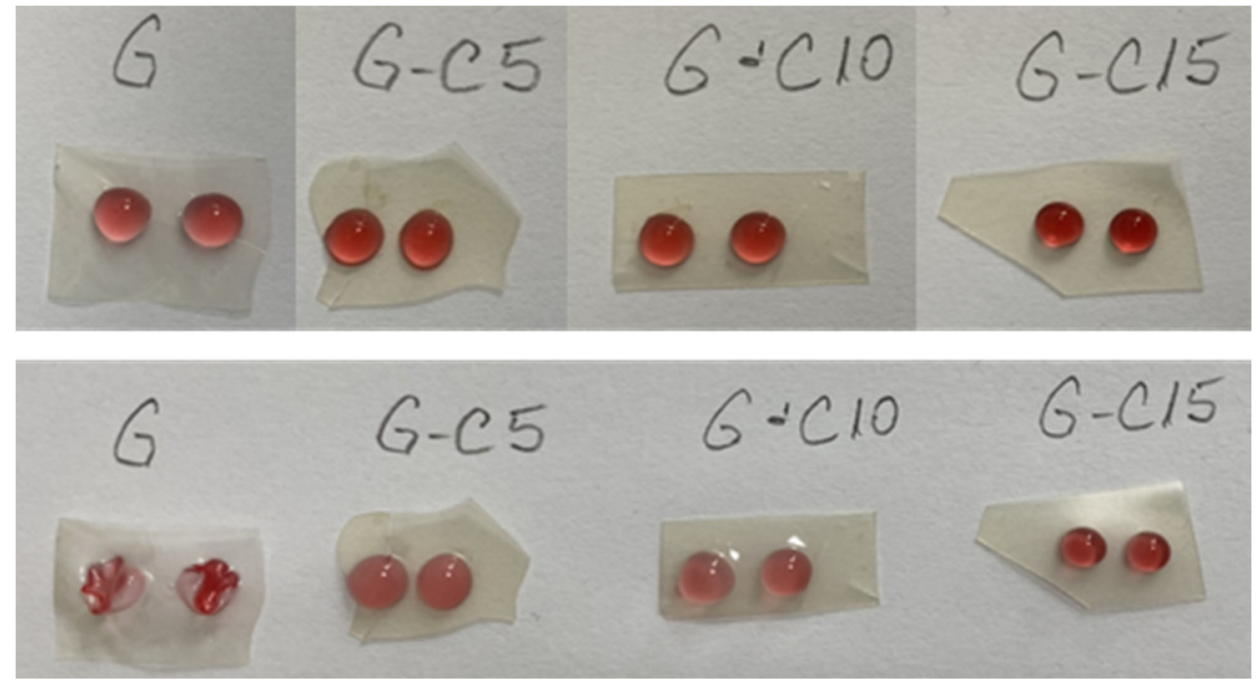

Figure 10. The water droplets on the surface of the films.

With the exception of gelatin film where the droplets were quickly absorbed, it was observed that the droplets remained on the surface of the nanocomposite films, presenting a low degree of absorption, and the dry-in time was of $30-35 \mathrm{~min}$. This is due to the increasing resistance of the films reinforced with CNC compared to the neat gelatin film, where water droplets caused its dissolution. Another study [22] observed that the droplets remained on the surface of the carrageenan $\mathrm{CNC}$ films, presenting a low degree of absorption and having a dry-in time of about $40-45 \mathrm{~min}$.

\subsection{Evaluation of Seed Coating Influence on Seed Germination}

\subsubsection{Compatibility Test}

To be used as carriers for biofertilizers, the polymer matrices have to be compatible with them. It is known that the success of a bioformulation depends both on the microbial load and its survival mechanism, as well as on the compatible carriers used for the development of the formulation. Therefore, apart from a formulations' storage stability, a non-compatible carrier can unfavorably affect the efficacy of the biocontrol agent.

In the present study, the compatibility between G and GC mixtures with T. harzianum KUEN 1585 (T) was determined.

From Figure 11, it can be observed that the polymeric coating did not inhibit the growth of T. harzianum KUEN 1585; moreover, the fungi developed on all the culture mediums, with higher colonial density towards the periphery of the petri dish in all cases. Therefore, both G and nanocomposite GCs were proven to be efficient carrier sources, as well as a nutrient source to the bio-agent.

Cortés-Rojas et al. [52] evaluated the T. koningiopsis spore compatibility with different polymers. They observed that alginate and potato starch showed the highest germination values for T. koningiopsis and the spores survival rate is related to the protection that polymers provide to the drying process and the moisture retention capacity during storage. 


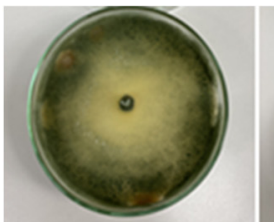

PDA+T

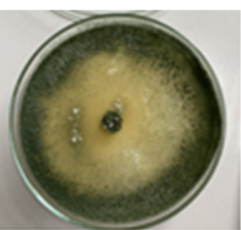

PDA-G+T

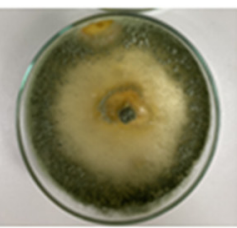

PDA-GC5+T

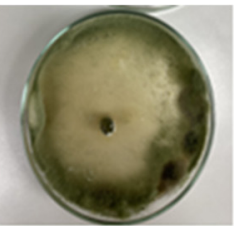

PDA-GC10+T

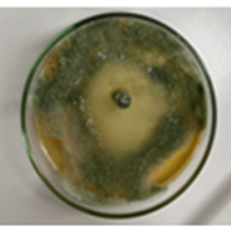

PDA-GC15+T

Figure 11. Growth of T. harzianum KUEN 1585 on PDA medium poisoned with G and GC mixtures on 7 th day.

\subsubsection{Viability of T. harzianum KUEN 1585 on Corn Seeds Test}

Usually, gelatin and pectin are used as water and air barrier films to extend the shelf life of fruits and vegetables, therefore they are considered good candidates for the microbial survival of the seeds by creating an environment that protects them from water vapor or reactive oxygen agents. Aside from a protecting role, these polymers are a good source of nutrients both for the microbes and the developing plants [52].

T. harzianum, in their natural environment, colonizes plant roots without apparent adverse reactions $[48,49]$. From Figure 12 it can be seen that after seven days the spores are viable on the seeds surface, because they improved the development of the roots. Seeds treated just with T. harzianum spores developed shorter roots (around $2 \mathrm{~cm}$ long), while seeds covered with gelatin developed roots with lengths between $5 \mathrm{~cm}(\mathrm{G}+\mathrm{T})$ and $8 \mathrm{~cm}$ $(\mathrm{GC} 10+\mathrm{T})(7 \mathrm{~cm}-\mathrm{GC} 15+\mathrm{T}$ and $6 \mathrm{~cm}-\mathrm{GC} 5+\mathrm{T})$. Therefore, when the fungal spores were added into the nanocomposite matrix, they led to an increase of the seed's roots compared to simple fungal spores. As mentioned before, the nanocomposite matrix acted also as a nutrient for the fungi and plant. The best performance was identified for the GC10 + T nanocomposite formulation.
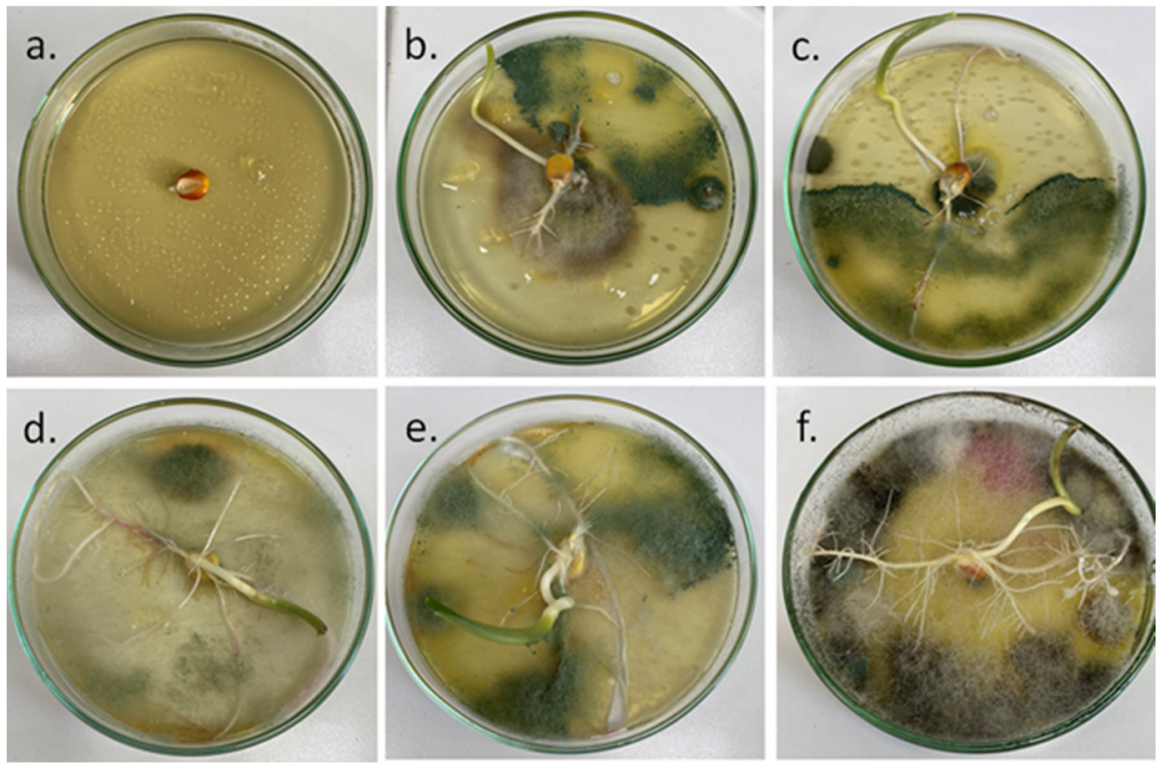

Figure 12. Viability test: corn seed on the first day (a), seeds on the 7 th day $(\mathbf{b}-\mathbf{f})$ : seeds treated with T. harzianum KUEN 1585 (b), G + T (c) GC5 + T (d), GC10 + T (e), GC15 + T (f).

Our findings agree with the study of Swaminathan et al. [53]. They inoculated fungal spores on different polymeric formulations and observed that the survival time and the number of spores adhering to formulations was higher in case of xanthan gum, but in extreme conditions, like $30{ }^{\circ} \mathrm{C}$ and $79 \% \mathrm{RH}$, the best spore survival was observed for the starch formulation. Even though they did not use gelatin or CNCs in their study, we observed improved survival time and development of the plant roots which were similar, therefore, both gelatin and CNCs are great candidates for this type of formulation. 


\subsubsection{Germination Test}

To germinate, a seed must be kept in an environment that favors its development. The conditions that must be fulfilled are the existence of an adequate amount of water, temperature range and light (in some cases) [53]. To assess the impact of seed treatment and nanocomposite coating on the corn seeds, the germination percentage (as a measure of the extent to which the seeds have germinated), speed of germination (as a measure of the speed when the germination process has ended) and root length were measured. In Figure 13 are presented the seeds placed in germination chamber and in 7th day of germination.

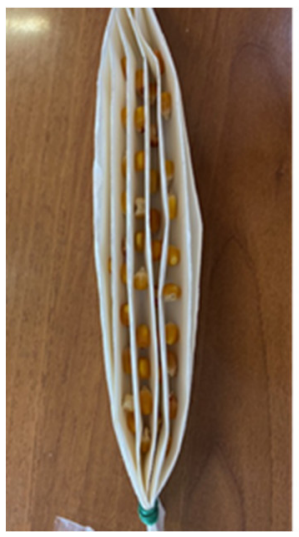

(a)

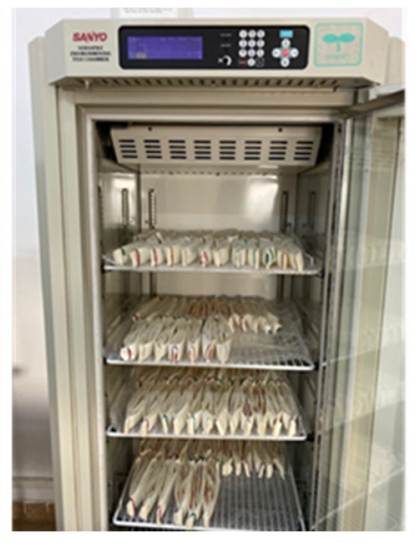

(b)

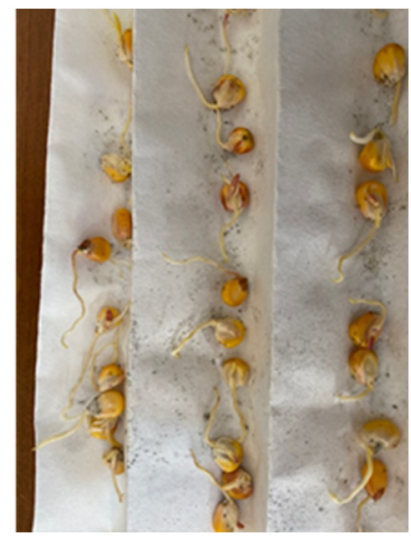

(c)

Figure 13. Seeds in paper towel for germination test (a), seeds placed in the germination chamber (b) and germinated seeds on 7 th day (c).

The seed quality parameters such as germination, speed of germination and root length were significantly influenced by the seed treatment, polymer coating and biofertilizer. T. harzianum is a free-living fungus which is common in root ecosystems and in soil, has been widely used as plant-growth enhancers, and also has an antagonistic effect against several pests $[54,55]$. López-Bucio et al. [56] suggested that T. harzianum acts under a mechanism of phytostimulation which involves a "multilevel communication with shoot and root systems", promoting root branching and nutrient uptake capacity and liberating active metabolites into the rhizosphere (auxins, small peptides, volatiles), thereby stimulating plant growth and yield.

The germination percentage of the seeds coated only with polymeric composite compared with seeds coated with T. harzianum KUEN 1585 are presented in Figure 14. It can be seen that the germination percentage is improved when seeds are coated with the polymeric material. The lowest $\mathrm{G} \%$ value is observed for control group (62\%) and seeds treated only with G and T. harzianum KUEN 1585, respectively. Increasing the CNC content in the seed coating agent led to an increase in the G\% up to $92 \%$ for GC10 and $90 \%$ for GC15. This can be attributed to the more compact structure of the coating that remains closer to the seed for a longer time, enhancing the germinability [20]. Furthermore, when the biofertilizer was added in the seed-coating material, the germination percentage improved, especially for gelatin and GC5 (Figure 14a). This fact can be assigned to the faster decomposition of gelatin, which enhanced the development of the biofertilizer, thus improving the G\%. Moreover, in the case of seeds treated just with T. harzianum KUEN 1585, the G\% was not improved, being an indicator that the development of the biofertilizer is influenced by the presence of the coating, which maintains the spores close to the seeds and may be acting as a nutrient for Trichoderma spp. after decomposition [20]. At the same time, the speed of germination was not significantly influenced by the polymeric coating, but when T. harzianum KUEN 1585 was added in the coating material the speed of germination improved, from 8.7 in the case of the control group up to almost 30 in the case of the $\mathrm{GC15}+\mathrm{T}$ group. This is an indicator that the germination process is accelerated due to the action of the biofertilizer [13]. Again, in this case, the values for speed of germination were 
higher when T. harzianum KUEN 1585 was incorporated in the coating material compared with the seeds treated just with the spores, indicating that the efficacy of the biofertilizer is improved when it is incorporated into the polymeric matrix [57].

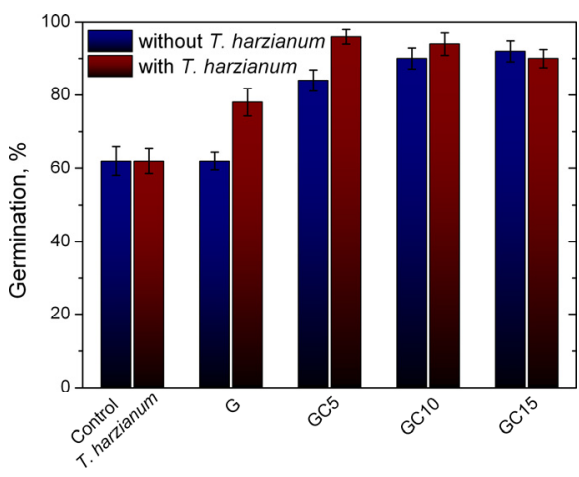

(a)

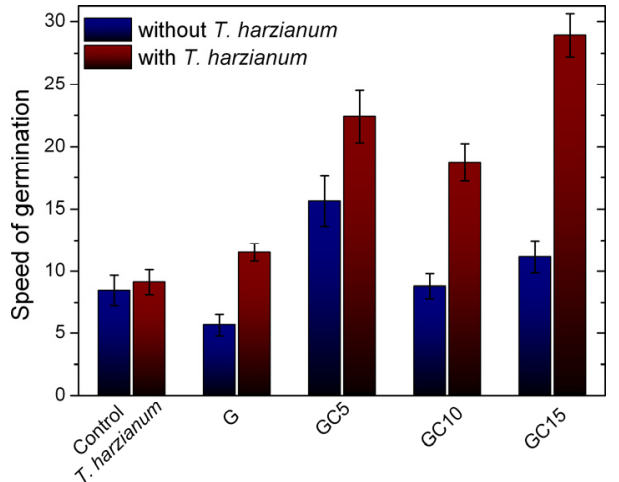

(b)

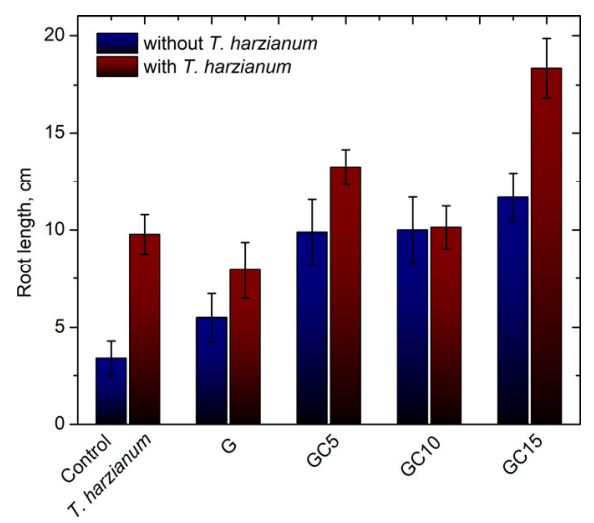

(c)

Figure 14. Germination percentage (a) speed of germination (b) and length of roots (c) of coated seeds with and without $T$. harzianum KUEN 1585 after 7 days of germination.

On the 7th day, the length of roots was measured, and it can be seen they are correlated with the speed of germination. Coating the seeds with the polymeric material led to formation of longer roots. In consequence, the shorter roots were measured for uncoated seeds $(3.38 \mathrm{~cm})$ and when increasing the reinforcing agent, the values of the root lengths increased, reaching $13.2 \mathrm{~cm}$ for the GC15 group. Moreover, the addition of the biofertilizer improved this parameter, with the roots being longer in all cases compared with the seeds treated only with the polymeric coating. The longest roots were measured for the seeds treated with GC15 with T. harzianum KUEN 1585, having an average of $18.3 \mathrm{~cm}$ compared with the control lot, where the average of roots length was only $3.4 \mathrm{~cm}$. The efficacy of Trichoderma spp. as a biofertilizer is given by the increasing of the nutrients' solubility and nutrient uptake capacity of the roots [58] and also their homogenous distribution in the plants $[59,60]$. Kipngeno et al. [15] treated tomato seeds with Bacillus subtilis and Trichoderma asperellum as a seed coating for management of damping-off in tomatoes and found that the coating was a good growth promoter.

\section{Materials and Methods}

\subsection{Materials}

Gelatin (G) from bovine skin (Type B) and glycerol (N99.5\%, MW: $92.02 \mathrm{~g} / \mathrm{mol}$ ) was purchased from Sigma Aldrich (St. Louis, MO, USA). Cellulose nanocrystals (CNCs) (sulfur content: $91 \mathrm{mmol}^{*} \mathrm{~kg}^{-1}$, Zeta-potential: $-28.5 \mathrm{mV}$ ) was produced from cellulose pulp by sulfuric acid hydrolysis and kindly supplied by Melodea Ltd. (Rehovot, Israel). Trichoderma harzianum KUEN 1585 spores (Trademark Sim Derma) were provided by ORBA Biokimya (Istanbul, Turkey). Double distilled water was used for the solubilization of gelatin and as a solvent.

\subsection{Film Preparation}

A solution of $3 \mathrm{wt} \%$ gelatin $(\mathrm{G})$ (prepared by the solubilization of the solid particles at $60{ }^{\circ} \mathrm{C}$ and $1500 \mathrm{rpm}$ for $1 \mathrm{~h}$ in distilled water) was mixed with cellulose nanocrystals (CNCs) suspension $1.5 \mathrm{wt} \%$ in different ratios to reach the final concentrations of $0 \%, 5 \%, 10 \%$ and $15 \%$ CNC dry weight. Glycerol was used as a plasticizer and was added in the final solution (30\% based on dry weight of components). The final mixture was homogenized by using magnetic stirring for $30 \mathrm{~min}$ at $60^{\circ} \mathrm{C}$ and $1500 \mathrm{rpm}$ and then mixed for 5 min with an ultraturax at $10,000 \mathrm{rpm}$ to ensure a complete homogenization of the components in the blended solution. The resulting solutions were poured in Petri dishes and then dried 
at $45^{\circ} \mathrm{C}$ for $24 \mathrm{~h}$. The thickness of the films was of $0.15 \pm 0.015 \mathrm{~mm}$. The codes and the composition of nanocomposite films are presented in Table 1.

Table 1. Sample codes and compositions.

\begin{tabular}{ccc}
\hline Code & G, \% & CNC, \% \\
\hline G & 100 & - \\
GC5 & 95 & 5 \\
GC10 & 90 & 10 \\
GC15 & 85 & 15 \\
\hline
\end{tabular}

\subsection{Film Characterization}

\subsubsection{Fourier Transform Infrared Spectroscopy}

The ATR-FTIR spectra were recorded at $4 \mathrm{~cm}^{-1}$ resolution in the $4000-500 \mathrm{~cm}^{-1}$ region on a Bruker ALPHA FTIR spectrometer using a diamond crystal. Five recordings were performed for each sample and the evaluations were made based on the average spectrum.

\subsubsection{X-ray Diffraction}

The diffractograms were recorded on a Diffractometer D8 ADVANCE (Bruker AXS, Germany), using the $\mathrm{CuK} \alpha$ radiation. The working conditions were $40 \mathrm{kV}, 30 \mathrm{~mA}, 2 \mathrm{~s} / \mathrm{step}$, and $0.02^{\circ}$ /step. All diffractograms were recorded in the 10-40 $2 \theta$ degrees range at room temperature.

\subsubsection{Scanning Electron Microscope}

The composite films were investigated using a scanning electron microscope (S4800 field emission SEM, Hitachi, UK). Each film was attached to SEM aluminum stub before being gold-coated for $90 \mathrm{~s}$ using a sputter coater (EMITECH K550X, Quorumtech, UK). During imaging, $3 \mathrm{kV}$ and $8.5 \mathrm{~mm}$ were used as the acceleration voltage and observation distance.

\subsubsection{Water Vapor Sorption Measurements}

Before testing, the samples were maintained in an oven for $24 \mathrm{~h}$ at $45^{\circ} \mathrm{C}$ to reach the constant mass. Further, the samples were placed in desiccators with different $\mathrm{RH}$ values $(3.5 \%, 8.5 \%, 16 \%, 25 \%, 36 \%, 45 \%, 54 \%, 59 \%, 69 \%, 75 \%, 80 \%, 85 \%, 92 \%$ and $100 \%)$, obtained by saturated salt solutions, at $25 \pm 1{ }^{\circ} \mathrm{C}$ in a conditioned room. To record the exact values, a LogTag thermohygrometer was placed in each desiccator. Each sample was maintained at a certain RH until it reached a constant mass, then was weighed and transferred to the next container with a higher RH. The moisture content was calculated using the Equation (1) [42]:

$$
\mathrm{MC} \%=[(\mathrm{Mf}-\mathrm{Mi})] \div \mathrm{Mi} \times 100
$$

where: $\mathrm{MC}$ is equilibrium moisture content, $\mathrm{Mf}$ is final mass and Mi is initial (dry) mass of the samples.

To identify the interactions taking place between the water and films, the NIR spectra were obtained using a PHAZIR Handheld Near-Infrared Analyzer (Thermo Fisher Scientific-Portable Optical Analysis, Waltham, MA, USA) in the range 1600-2400 nm, resolution $11 \mathrm{~nm}$, scan number: 6 .

\subsubsection{Moisture Adsorption Test}

Dried samples were placed in a desiccator at $57 \% \mathrm{RH}$. The samples were weighed every hour until a constant mass was registered and the moisture content was calculated using the previous equation. 


\subsubsection{Determination of Swelling Degree}

Dried films were immersed in distilled water at $25{ }^{\circ} \mathrm{C}$ and weighted periodically at 5 , $10,15,30,45,60,90,120,180,240$ and $360 \mathrm{~min}(6 \mathrm{~h})$. The water uptake (WU\%) and percentage of absorbed water ( $\mathrm{M} \%$ ) were calculated by using the same type of Equation (2) [42]:

$$
\mathrm{WU} \%, \mathrm{M} \%=[(\mathrm{Mf}-\mathrm{Mi})] \div \mathrm{Mi} \times 100
$$

where Mf is the final mass and Mi is the initial (dry) mass of the sample.

\subsubsection{Contact Angle Measurements}

The static contact angles were determined by the sessile drop method, at room temperature and controlled humidity, within $30 \mathrm{~s}$ (the time corresponding to a metastable equilibrium between the liquid droplet and the tested surfaces) using a CAM-200 instrument from KSV, Finland. The measurements were performed using $1 \mu \mathrm{L}$ drop of water on the film surface. Contact angle measurements were taken on five different locations on the surface and the average values were further considered. All measurements were done on the side of the films in contact with the air during drying.

\subsubsection{Dry-In Time of Water Droplets on the Surfaces and Absorption}

To evaluate the dry-in time of a water droplet on the surface of the film samples, three droplets with comparable size were placed with a syringe on the surface of the films. To make the experiment more visible, the water was mixed with red beet extract $(15 \%$ concentration) and the dry-in time of the droplets on the films surface was observed. By identifying the absorption of the droplets into the surface of the samples, the removability of the dried droplets was evaluated.

\subsection{Seed Coating}

In total, $2.5 \mathrm{~mL}$ from previous described solutions were added to $50 \mathrm{~g}$ corn seeds and mixed for 5 min. For seeds treated with the biocontrol agent, Trichoderma harzianum KUEN 1585 was added by $6 \times 10^{5} \mathrm{CFU} / 10 \mathrm{~g}$ seeds into the initial polymeric solution. The covered seeds were dried at room temperature for $24 \mathrm{~h}$.

\subsubsection{Compatibility Test}

For the compatibility test, the poisoned food technique was used to evaluate the influence of the polymeric matrix on the development on T. harzianum spores [51]. For that, in the PDA medium (agar, $15 \mathrm{~g} / \mathrm{L}, \mathrm{NaCl}, 5 \mathrm{~g} / \mathrm{L}$, tryptone, $10 \mathrm{~g} / \mathrm{L}$, yeast extract, $5 \mathrm{~g} / \mathrm{L}$ ) $1.5 \mathrm{wt} \%$ solutions of G, GC5, GC10 and GC15 with a concentration of $1 \%$ were added. On the obtained medium, T. harzianum KUEN 1585 was placed, and the Petri dishes were kept at $25^{\circ} \mathrm{C}$ for 7 days. Colony morphology and mycelial growth were observed daily. A Petri dish with PDA only with T. harzianum KUEN 1585 was used as a control. The influence of polymeric solutions on the development of T. harzianum KUEN 1585 was observed after 7 days. Twice the experiments were carried out in a randomized fashion in three replications for each treatment.

\subsubsection{Viability Test}

To observe if the T. harzianum KUEN 1585 spores are still viable on the corn seeds, for each treatment one seed was placed in a Petri dish with PDA medium. After 7 days at $25^{\circ} \mathrm{C}$, the development of the T. harzianum KUEN 1585 spores was evaluated [61].

\subsubsection{Germination Test}

The seeds were placed at $25^{\circ} \mathrm{C}, 85 \% \mathrm{RH}$, in the dark for 7 days in paper towels for assessing the germination and seed quality parameters. Daily germination counts were recorded until no further germination occurred [62]. The number of normal seedlings and 
the length of the roots were counted after the test period and the germination (\%) was calculated using the formula:

Germination $(\%)=$ Number of normal seedlings $/$ Total number of seeds $\times 100$

Speed of germination was calculated by the following formula [63]:

$$
\text { Speed of germination }=\mathrm{N} 1 / \mathrm{T} 1+\mathrm{N} 2 / \mathrm{T} 2+\mathrm{N} 3 / \mathrm{T} 3+\ldots+\mathrm{Nx} / \mathrm{Tx}
$$

where $\mathrm{N}$ is the number of seeds germinated in days " $\mathrm{T}$ ".

\subsubsection{Statistical Analysis}

A total of 100 seeds were used for each method: seed germination, speed of germination and root length determinations. Data were analyzed by analysis of variance. Means were separated by Fisher's least significant difference (LSD) and $p$ values $<0.05$ were considered significant.

\section{Conclusions}

In this work, a new seed coating material using natural polymers was synthetized and characterized. By adding CNC as a reinforcing agent in gelatin film a more compact structure was obtained due to the chemical interactions established between the film components, mainly hydrogen bonds, as observed by FTIR and XRD. The good compatibility and homogenous distribution of CNC in the polymeric matrix demonstrated by SEM caused a tortuous path for the water vapor molecules to enter through the films, causing an improvement of resistance of the films with water molecules. Furthermore, to enhance the parameters that characterize seed germinability, Trichoderma spp. were immobilized in the seed coating matrix. It was observed that the biocontrol agent is compatible with the components of the nanocomposite films and remains viable on the seeds after coating. Moreover, treating the seeds with the biocontrol agent led to an improvement of $\mathrm{G} \%$ (from $62 \%$ in case of control group up to $96 \%$ in case of GC5 with T. harzianum) and speed of germination. The length of the roots increased in the case of seeds treated with T. harzianum compared with seeds treated just with polymeric material. The results showed that immobilization of the biocontrol agent in the coating material of corn seeds has a promising potential for use in the agricultural sector.

Author Contributions: Conceptualization, M.-C.P. and B.-I.D.; methodology, B.-I.D.; investigation, B.-I.D., V.S., G.M.; resources, S.Y.; writing—original draft preparation, B.-I.D.; writing—review and editing, M.-C.P. and V.S.; supervision, M.-C.P.; project administration, M.-C.P.; funding acquisition, M.-C.P. All authors have read and agreed to the published version of the manuscript.

Funding: This work was supported by the project M-ERA.NET2 COFUND—no.73/2017-Ecofriendly nanoclay, nanocellulose and MIP composites for microbial formulations-COMPIO.

Institutional Review Board Statement: Not applicable.

Informed Consent Statement: Not applicable.

Conflicts of Interest: The authors declare no conflict of interest.

Sample Availability: Samples of the nanocomposite matrix are available from the authors.

\section{References}

1. Li, X.; Liu, A.; Ye, R.; Wang, Y.; Wang, W. Fabrication of gelatin-laponite composite films: Effect of the concentration of laponite on physical properties and the freshness of meat during storage. Food Hydrocoll. 2015, 44, 390-398. [CrossRef]

2. Feng, T.; Su, Q.; Zhuang, H.; Ye, R.; Gu, Z.; Jin, Z. Ghost structures, pasting, rheological and textural properties between Mesona blumes gum and various starches. J. Food Qual. 2014, 37, 73-82. [CrossRef]

3. Chen, Y.; Ye, R.; Li, X.; Wang, J. Preparation and characterization of extruded thermoplastic zein-poly (propylene carbonate) film. Ind. Crop. Prod. 2013, 49, 81-87. [CrossRef] 
4. Pereda, M.; Ponce, A.G.; Marcovich, N.E.; Ruseckaite, R.A.; Martucci, J.F. Chitosan-gelatin composites and bi-layer films with potential antimicrobial activity. Food Hydrocoll. 2011, 25, 1372-1381. [CrossRef]

5. Monteiro, M.K.S.; dos Santos, F.K.G.; Leite, R.H.D.L.; Aroucha, E.; Vitoriano, J.O.; Oliveira, V.R.L. Hydrophilicity, solubility and optical properties in composite films of gelatin and bentonite clay in its natural form or modified. Mater. Sci. Forum 2018, 912, 136-140. [CrossRef]

6. Wang, Y.; Liu, A.; Ye, R.; Wang, W.; Li, X. Transglutaminase-induced crosslinking of gelatin-calcium carbonate composite films. Food Chem. 2015, 166, 414-422. [CrossRef] [PubMed]

7. Gómez-Guillén, M.C.; Perez-Mateos, M.; Gómez-Estaca, J.; López-Caballero, E.; Giménez, B.; Montero, P. Fish gelatin: A renewable material for developing active biodegradable films. Trends Food Sci. Technol. 2009, 20, 3-16. [CrossRef]

8. Suderman, N.; Isa, M.I.N.; Sarbon, N.M. The effect of plasticizers on the functional properties of biodegradable gelatin-based film: A review. Food Biosci. 2018, 24, 111-119. [CrossRef]

9. Yadav, M.; Chiu, F.-C. Cellulose nanocrystals reinforced $\mathrm{k}$-carrageenan based UV resistant transparent bionanocomposite films for sustainable packaging applications. Carbohydr. Polym. 2019, 211, 181-194. [CrossRef]

10. Gicquel, E.; Martin, C.; Yanez, J.G.; Bras, J. Cellulose nanocrystals as new bio-based coating layer for improving fiber-based mechanical and barrier properties. J. Mater. Sci. 2017, 52, 3048-3061. [CrossRef]

11. Cacciotti, I.; Fortunati, E.; Puglia, D.; Kenny, J.M.; Nanni, F. Effect of silver nanoparticles and cellulose nanocrystals on electrospun poly (lactic) acid mats: Morphology, thermal properties and mechanical behavior. Carbohydr. Polym. 2014, 103, 22-31. [CrossRef]

12. Leite, L.S.; Ferreira, C.M.; Corrêa, A.C.; Moreira, F.K.; Mattoso, L.H. Scaled-up production of gelatin-cellulose nanocrystal bionanocomposite films by continuous casting. Carbohydr. Polym. 2020, 238, 116198. [CrossRef] [PubMed]

13. Accinelli, C.; Abbas, H.K.; Shier, W.T. A bioplastic-based seed coating improves seedling growth and reduces production of coated seed dust. J. Crop. Improv. 2018, 32, 1-13. [CrossRef]

14. Tekrony, D.M. Seeds: The delivery system for crop science. Crop. Sci. 2006, 46, 2263-2269. [CrossRef]

15. Kipngeno, P.; Losenge, T.; Maina, N.; Kahangi, E.; Juma, P. Efficacy of Bacillus subtilis and Trichoderma asperellum against Pythium aphanidermatum in tomatoes. Biol. Control 2015, 90, 92-95. [CrossRef]

16. Locatelli, G.O.; dos Santos, G.F.; Botelho, P.S.; Finkler, C.L.L.; Bueno, L.A. Development of Trichoderma sp. formulations in encapsulated granules (CG) and evaluation of conidia shelf-life. Biol. Control 2018, 117, 21-29. [CrossRef]

17. Nicolopoulou-Stamati, P.; Maipas, S.; Kotampasi, C.; Stamatis, P.; Hens, L. Chemical pesticides and human health: The urgent need for a new concept in agriculture. Front. Public Health 2016, 4, 148. [CrossRef]

18. Cacciotti, I.; Pallotto, F.; Scognamiglio, V.; Moscone, D.; Arduini, F. Reusable optical multi-plate sensing system for pesticide detection by using electrospun membranes as smart support for acetylcholinesterase immobilisation. Mater. Sci. Eng. C 2020, 111, 110744. [CrossRef] [PubMed]

19. Pedrini, S.; Merritt, D.; Stevens, J.; Dixon, K. Seed coating: Science or marketing spin? Trends Plant Sci. 2017, 22, 106-116. [CrossRef] [PubMed]

20. Accinelli, C.; Abbas, H.K.; Little, N.; Kotowicz, J.K.; Mencarelli, M.; Shier, W.T. A liquid bioplastic formulation for film coating of agronomic seeds. Crop. Prot. 2016, 89, 123-128. [CrossRef]

21. Bettiol, W. Biopesticide use and research in Brazil. Outlooks Pest Manag. 2011, 22, 280-283. [CrossRef]

22. Popescu, M.-C.; Dogaru, B.-I.; Sun, D.; Stoleru, E.; Simionescu, B.C. Structural and sorption properties of bio-nanocomposite films based on K-carrageenan and cellulose nanocrystals. Int. J. Biol. Macromol. 2019, 135, 462-471. [CrossRef] [PubMed]

23. Popescu, M.-C.; Vasile, C.; Filip, D.; Macocinschi, D.; Singurel, G. Characterization by Fourier transform infrared spectroscopy of polyethylene adipate/cholesteryl palmitate blends. J. Appl. Polym. Sci. 2004, 94, 1156-1163. [CrossRef]

24. Popescu, C.-M.; Jones, D.; Schalnat, J.; Segerholm, K.; Henriksson, M.; Westin, M. Structural characterization and mechanical properties of wet-processed fibreboard based on chemo-thermomechanical pulp, furanic resin and cellulose nanocrystals. Int. J. Biol. Macromol. 2020, 145, 586-593. [CrossRef] [PubMed]

25. Taheri, P.; Jahanmardi, R.; Koosha, M.; Abdi, S. Physical, mechanical and wound healing properties of chitosan/gelatin blend films containing tannic acid and/or bacterial nanocellulose. Int. J. Biol. Macromol. 2020, 154, 421-432. [CrossRef]

26. Kong, J.; Yu, S. Fourier transform infrared spectroscopic analysis of protein secondary structures. Acta Biochim. Biophys. Sin. 2007, 39, 549-559. [CrossRef]

27. Li, K.; Jin, S.; Chen, H.; Li, J. Bioinspired interface engineering of gelatin/cellulose nanofibrils nanocomposites with high mechanical performance and antibacterial properties for active packaging. Compos. Part B Eng. 2019, 171, 222-234. [CrossRef]

28. Hashim, D.; Man, Y.C.; Norakasha, R.; Shuhaimi, M.; Salmah, Y.; Syahariza, Z. Potential use of Fourier transform infrared spectroscopy for differentiation of bovine and porcine gelatins. Food Chem. 2010, 118, 856-860. [CrossRef]

29. Popescu, M.-C.; Vasile, C.; Craciunescu, O. Structural analysis of some soluble elastins by means of FT-IR and 2D IR correlation spectroscopy. Biopolymers 2010, 93, 1072-1084. [CrossRef]

30. Ngarize, S.; Herman, H.; Adams, A.; Howell, N. Comparison of changes in the secondary structure of unheated, heated, and highpressure-treated $\beta$-lactoglobulin and ovalbumin proteins using Fourier transform Raman spectroscopy and self-deconvolution. J. Agric. Food Chem. 2004, 52, 6470-6477. [CrossRef]

31. Omrani-Fard, H.; Abbaspour-Fard, M.H.; Khojastehpour, M.; Dashti, A. Gelatin/whey protein-potato flour bioplastics: Fabrication and evaluation. J. Polym. Environ. 2020, 28, 2029-2038. [CrossRef] 
32. Ahammed, S.; Liu, F.; Khin, M.N.; Yokoyama, W.H.; Zhong, F. Improvement of the water resistance and ductility of gelatin film by zein. Food Hydrocoll. 2020, 105, 105804. [CrossRef]

33. Okuyama, K. Revisiting the molecular structure of collagen. Connect. Tissue Res. 2008, 49, 299-310. [CrossRef]

34. Sun, D.; Onyianta, A.J.; O’Rourke, D.; Perrin, G.; Popescu, C.-M.; Saw, L.H.; Cai, Z.; Dorris, M. A process for deriving high quality cellulose nanofibrils from water hyacinth invasive species. Cellulose 2020, 27, 3727-3740. [CrossRef]

35. Popescu, M.-C.; Dogaru, B.-I.; Popescu, C.-M. Effect of cellulose nanocrystals nanofiller on the structure and sorption properties of carboxymethyl cellulose-glycerol-cellulose nanocrystals nanocomposite systems. Materials 2020, 13, 2900. [CrossRef]

36. Kwak, H.W.; Lee, H.; Park, S.; Lee, M.E.; Jin, H.-J. Chemical and physical reinforcement of hydrophilic gelatin film with di-aldehyde nanocellulose. Int. J. Biol. Macromol. 2020, 146, 332-342. [CrossRef]

37. Pereira, P.F.M.; Picciani, P.H.S.; Calado, V.M.A.; Tonon, R.V. Gelatin-based nanobiocomposite films as sensitive layers for monitoring relative humidity in food packaging. Food Bioprocess Technol. 2020, 13, 1063-1073. [CrossRef]

38. Li, H.; Shi, H.; He, Y.; Fei, X.; Peng, L. Preparation and characterization of carboxymethyl cellulose-based composite films reinforced by cellulose nanocrystals derived from pea hull waste for food packaging applications. Int. J. Biol. Macromol. 2020, 164, 4104-4112. [CrossRef] [PubMed]

39. Mondragon, G.; Peña-Rodriguez, C.; González, A.; Eceiza, A.; Arbelaiz, A. Bionanocomposites based on gelatin matrix and nanocellulose. Eur. Polym. J. 2015, 62, 1-9. [CrossRef]

40. Hanani, Z.N.; Roos, Y.; Kerry, J. Use and application of gelatin as potential biodegradable packaging materials for food products. Int. J. Biol. Macromol. 2014, 71, 94-102. [CrossRef] [PubMed]

41. Van der Wel, G.; Adan, O. Moisture in organic coatings-A review. Prog. Org. Coat. 1999, 37, 1-14. [CrossRef]

42. Popescu, M.-C.; Dogaru, B.-I.; Popescu, C.-M. The influence of cellulose nanocrystals content on the water sorption properties of bio-based composite films. Mater. Des. 2017, 132, 170-177. [CrossRef]

43. Ooi, S.Y.; Ahmad, I.; Amin, M.C.I.M. Cellulose nanocrystals extracted from rice husks as a reinforcing material in gelatin hydrogels for use in controlled drug delivery systems. Ind. Crop. Prod. 2016, 93, 227-234. [CrossRef]

44. George, J.; Siddaramaiah, J. High performance edible nanocomposite films containing bacterial cellulose nanocrystals. Carbohydr. Polym. 2012, 87, 2031-2037. [CrossRef]

45. Syahida, S.N.; Ismail-Fitry, M.R.; Ainun, Z.M.A.; Hanani, Z.A.N. Effects of palm wax on the physical, mechanical and water barrier properties of fish gelatin films for food packaging application. Food Packag. Shelf Life 2020, 23, 100437. [CrossRef]

46. Kavoosi, G.; Rahmatollahi, A.; Dadfar, S.M.M.; Purfard, A.M. Effects of essential oil on the water binding capacity, physicomechanical properties, antioxidant and antibacterial activity of gelatin films. LWT 2014, 57, 556-561. [CrossRef]

47. Santos, T.M.; Souza Filho, M.d.S.M.; Cáceres, C.A.; Rosa, M.F.; Morais, J.P.S.; Pinto, A.M.; Azeredo, H.M. Fish gelatin films as affected by cellulose whiskers and sonication. Food Hydrocoll. 2014, 41, 113-118. [CrossRef]

48. Miao, C.; Hamad, W.Y. In-situ polymerized cellulose nanocrystals (CNC)—Poly (l-lactide) (PLLA) nanomaterials and applications in nanocomposite processing. Carbohydr. Polym. 2016, 153, 549-558. [CrossRef] [PubMed]

49. Maroufi, L.Y.; Ghorbani, M.; Tabibiazar, M.; Mohammadi, M.; Pezeshki, A. Advanced properties of gelatin film by incorporating modified kappa-carrageenan and zein nanoparticles for active food packaging. Int. J. Biol. Macromol. 2021, 183, 753-759. [CrossRef]

50. Xiao, Y.; Liu, Y.; Kang, S.; Wang, K.; Xu, H. Development and evaluation of soy protein isolate-based antibacterial nanocomposite films containing cellulose nanocrystals and zinc oxide nanoparticles. Food Hydrocoll. 2020, 106, 105898. [CrossRef]

51. De Souza Coelho, C.C.; Silva, R.B.S.; Carvalho, C.W.P.; Rossi, A.L.; Teixeira, J.A.; Freitas-Silva, O.; Cabral, L.M.C. Cellulose nanocrystals from grape pomace and their use for the development of starch-based nanocomposite films. Int. J. Biol. Macromol. 2020, 159, 1048-1061. [CrossRef]

52. Cortés-Rojas, D.; Beltrán-Acosta, C.; Zapata-Narvaez, Y.; Chaparro, M.; Gómez, M.; Cruz-Barrera, M. Seed coating as a delivery system for the endophyte Trichoderma koningiopsis Th003 in rice (Oryza sativa). Appl. Microbiol. Biotechnol. 2021, 105, 1889-1904. [CrossRef] [PubMed]

53. Swaminathan, J.; van Koten, C.; Henderson, H.; Jackson, T.; Wilson, M. Formulations for delivering Trichoderma atroviridae spores as seed coatings, effects of temperature and relative humidity on storage stability. J. Appl. Microbiol. 2016, 120, 425-431. [CrossRef] [PubMed]

54. Yonsel, S..; Demir, M. Dressing of wheat seeds with the PGP fungus Trichoderma harzianum KUEN 1585. Soil Water J. 2013, 2, 1789-1796.

55. Mancini, V.; Romanazzi, G. Seed treatments to control seedborne fungal pathogens of vegetable crops. Pest Manag. Sci. 2014, 70, 860-868. [CrossRef] [PubMed]

56. López-Bucio, J.; Pelagio-Flores, R.; Herrera-Estrella, A. Trichoderma as biostimulant: Exploiting the multilevel properties of a plant beneficial fungus. Sci. Hortic. 2015, 196, 109-123. [CrossRef]

57. Yonsel, S..; Sevim, M. Microbial seed dressing to increase grain yield and quality. In Proceedings of the 15th International Cereal and Bread Congress, Istanbul, Turkey, 17-21 April 2016.

58. Yonsel, Ş.; Sevim, M. Microbial dressing of sunflower seeds with Trichoderma harzianum KUEN 1585. In Proceedings of the 19th International Sunflower Conference, Edirne, Turkey, 29 May-3 June 2016.

59. Yonsel, S..; Demir, M. Coating of wheat seeds with the PGP fungus Trichoderma harzianum KUEN 1581. New Biotechnol. 2012, 29, S23. [CrossRef] 
60. Kader, M.A. A comparison of seed germination calculation formulae and the associated interpretation of resulting data. J. Proc. R. Soc. N. S. Wales 2005, 138, 65-75.

61. Supriya, P.; Sridhar, K.; Ganesh, S. Fungal decontamination and enhancement of shelf life of edible split beans of wild legume Canavalia maritima by the electron beam irradiation. Radiat. Phys. Chem. 2014, 96, 5-11. [CrossRef]

62. Thube, S.H.; Mahapatro, G.K.; Kumar, M.B.A. In vitro evaluation of insecticides, bio-fungicide and bio-fertilizer for strategic and eco-friendly combinatorial seed treatments in chickpea. Proc. Natl. Acad. Sci. India Sect. B Biol. Sci. 2018, 88, 645-654. [CrossRef]

63. Raju, K.; Radhika, K.; Reddy, K.B.; Naik, V.S. Assessment of the impact of seed treatment and polymer coating on germination and seedling vigour of maize hybrid, DHM 117. Int. J. Chem. Stud. 2019, 7, 373-377. 